\title{
BACKGROUNDED AGENTS IN CATALAN SIGN LANGUAGE (LSC): PASSIVES, MIDDLES, OR IMPERSONALS?
}

\author{
GEMMA BARBERÀ \\ Patricia Cabredo HofherR \\ UMR 7023 (CNRS/Paris 8) \\ UMR 7023 (CNRS/Paris 8)
}

\begin{abstract}
This article proposes that at least two agent-backgrounding operations with different syntactic and semantic properties have to be distinguished in Catalan Sign Language (LSC): the HIGH-LOCUS CONSTRUCTION and the NONAGREEING CENTRAL CONSTRUCTION. We show that the high-locus construction is a transitive structure with a nonspecific subject. We propose to analyze this construction as involving a null pro-subject, licensed by agreement and interpreted as an impersonal third plural, as in other agent-backgrounding constructions with an impersonal third plural subject, which are crosslinguistically restricted to human interpretation. We propose that the nonagreeing construction is an intransitivized verb form that allows passive interpretations with agents and causes and anticausative interpretations comparable to middle voice.*

Keywords: agent backgrounding, Catalan Sign Language (LSC), middle, nonspecificity, passive, R-impersonal, transitivity
\end{abstract}

1. Introduction. Agent-backgrounding constructions have been studied extensively in the linguistic literature on spoken languages. The linguistic means of expressing agent backgrounding include a wide variety of strategies, from verbal marking as in passives (see e.g. Siewierska 1984; see also Keenan \& Dryer 2007 and references cited there) and middles (Kemmer 1993) to nominal strategies such as dedicated human impersonal pronouns (Koenig 1999, Zifonun 2000), null pronouns in partial pro-drop languages (Cabredo Hofherr 2006, Holmberg 2005), impersonal uses of personal pronouns (Bolinger 1979, Kitagawa \& Lehrer 1990, Yule 1982), and generalizing nouns (people/ a person) (Siewierska 2008, 2011; see also Malamud 2012, and Gast \& van der Auwera 2013 for a discussion of nominal agent-backgrounding strategies). For sign languages it remains controversial which constructions should be analyzed as passives (Kegl 1990, Janzen et al. 2001). Impersonal reference in sign languages has only recently become the subject of dedicated studies (Barberà \& Quer 2013).

In this article we argue that for Catalan Sign Language (llengua de signes catalana, LSC) at least two agent-backgrounding operations with different syntactic and semantic properties have to be distinguished: the HIGH-LOCUS CONSTRUCTION and the NONAGREEING CENTRAL CONSTRUCTION. In the high-locus construction the verb appears without a lexical subject, with verbal subject agreement established with a high lateral locus (glossed up in 1). In the nonagreeing central construction, the verb is articulated in central signing space (glossed $c$ in 2 ) without a lexically introduced subject. ${ }^{1}$

\footnotetext{
* The present work was financed by the Franco-German ANR-DFG project 'Towards a typology of human impersonal pronouns' (ANR-11-FRAL-0011, 2012-2015). We would like to thank Matthew Baerman, Marion Blondel, Volker Gast, Meltem Kelepir, Vadim Kimmelman, Elena Koulidobrova, Brenda Laca, Josep Quer, Annie Risler, Markus Steinbach, the editors of Language, and two anonymous referees for their useful comments and interesting discussions on previous versions of this work. We are grateful to Delfina Aliaga and Santiago Frigola for the elicitation sessions and for the discussions on LSC. We thank the audiences at FEAST (Venice, June 2014), the workshop Langues des Signes et R-Impersonnels (Paris, February 2015), the Colloquium on Generative Grammar (Bayonne, May 2015), and the workshop R-Impersonals in Sign Language (Barcelona, June 2015) for comments on previous versions. All remaining mistakes are our responsibility.

${ }^{1}$ This article follows the usual glossing conventions in the sign language literature, representing manual signs by the capitalized word corresponding to the translation of the sign. The abbreviations used in the glosses are the following (\# is a placeholder for the loci in signing space corresponding to first-, second-, and third-person referents): IX\#: index pointing sign, \#-VERB-\#: verb agreeing with subject and object; subindices mark localization in signing space: lo: low, up: up, ip: ipsilateral, cl: contralateral, c: center; lower 
(1) BIKE STEAL-3 $_{\text {up }}$

(LSC; high-locus construction)

'They stole the bike.'

(2) POT FLOWER BREAK .

'The flower pot broke/was broken.'

(LSC; nonagreeing central construction)

Based on the syntactic and semantic properties of the construction in 1, we claim that this structure does not behave as a passive construction: it does not involve reduction of transitivity, and there is no evidence that the object is promoted to subject. According to our analysis, the agent-backgrounding effect in 1 is due to a referentially deficient subject without any change in transitivity, comparable to a transitive construction with an unspecified agent, as in the Spanish example and English translation in 3.

(3) Robaron su bicicleta.

(Spanish)

stole.PFV.PST.3PL POSs.3sg bike

'They stole his bike.'

The nonagreeing central construction in 2 differs from the high-locus construction in 1 in that it is compatible with a wide range of readings, including anticausative, middle stative, and eventive passive. We propose to analyze this structure as an intransitive nonactive construction comparable to a middle verb, allowing anticausative, stativemiddle, and middle passive readings. Neither construction is therefore a passive proper: the high-locus construction is a transitive construction with an R-impersonal subject, while the nonagreeing construction is an intransitive nonactive construction comparable to a middle verb that may but need not imply an agent.

The article is structured as follows. We first briefly summarize a number of salient properties of sign languages with respect to reference and argument structure that have been identified in the literature $(\$ 2)$. We then review the previous literature on potential passive structures in different sign languages in $\S 3$, identifying a range of features associated with different agent-backgrounding constructions. Section 4 gives a summary of the contrasts found between passive constructions, middles, and R(eferential)-impersonal subjects crosslinguistically in spoken languages. We analyze the syntactic and semantic properties of the high-locus construction and the nonagreeing central construction in Catalan Sign Language (LSC) in $§ 5$, develop the syntactic analysis in $\S 6$, and then conclude $(\$ 7)$.

2. Reference and argument structure in Sign LANGUAGes. Sign languages make use of the three-dimensional space in front of the signer's body for grammatical purposes. Signs are articulated in the signing space, which in Western sign languages is generally constrained to the horizontal and the frontal plane in front of the signer's torso. The body of the signer is also a possible location for the articulation of signs and as such is included in the extension of the signing space. As Klima and Bellugi (1979) stress, not only is signing space used for articulatory reasons as a space where the hands and arms can move, but, more importantly, this space also carries linguistic meaning. At the morphosyntactic level, for example, signs are modulated in space for grammatical purposes to express number, person, and also the arguments of the verb.

Determiner phrases (DPs) are associated with an area on the horizontal plane called the Locus (Klima \& Bellugi 1979). In a sentence like 4a below, the locus of the subject is established in the ipsilateral area of signing space (the area located at the dominant

indexed letters $(\mathrm{i}, \mathrm{j} . .$.$) mark coreference relations; CL is used for classifier construction, followed by the kind$ of classifier (ent for entity classifier, hand for handling classifier, limb for limb classifier) and a rough meaning description. A line above the glosses indicates the scope of nonmanuals: br: brow raise, eg: eyegaze, rs: role shift. Glosses for spoken language examples follow the Leipzig glossing rules and abbreviations (http:// www.eva.mpg.de/lingua/resources/glossing-rules.php). 
hand of the signer, i.e. the right hand for right-handed signers, glossed with the subscript ip), while the locus of the object is in the contralateral area (the area located at the nondominant hand, i.e. the left hand for right-handed signers, glossed with the subscript $\mathrm{cl}$ ). The agreeing verb SEE in 4a moves from the ipsilateral locus of the subject to the contralateral locus of the object. The direction of the movement component of the predicate has a grammatical meaning, as it marks the syntactic functions of the arguments: for SEE the movement path is from subject to object. Inverting the movement path associated with the verb, as in $4 b$, inverts the function of the arguments. Furthermore, as illustrated in $4 \mathrm{c}$, the loci of the arguments are also used to express coreferential relations.

(4) a. JOHN ip MARIA $_{\mathrm{cl}} \mathbf{3}_{\mathrm{ip}}-\mathbf{S E E -} \mathbf{3}_{\mathrm{cl}}$.

'John saw Maria.'

b. $\mathrm{JOHN}_{\mathrm{ip}}$ MARIA $_{\mathrm{cl}} \mathbf{3}_{\mathrm{cl}}$-SEE-3 $\mathbf{3}_{\mathrm{ip}}$.

'Maria saw John.'

c. YESTERDAY JOHN ${ }_{\text {ip }}$ MARIA $_{\mathrm{cl}} 3_{\mathrm{ip}}-\mathrm{SEE}-3_{\mathrm{cl}}$. TODAY IX $\mathbf{3}_{\mathrm{cl}}$ $\mathbf{3}_{\text {ip }}$-INVITE- $\mathbf{3}_{\mathrm{cl}}$.

'Yesterday John saw Maria. Today she invited him.'

In many verbs, called REGULAR AGREEING VERBS, the direction of movement is from the locus associated with the subject to the locus associated with the object. However, there is a small set of verbs, called BACKWARD AGREEING VERBS, which show the opposite pattern. With backward verbs the direction of the movement path is from the locus of the object to the locus of the subject, as in the case of INVITE in 4c. Not all predicates show agreement with their arguments, however. Based on the patterns of modulation observed, Padden (1990) classifies American Sign Language (ASL) verbs into three different types: plain verbs, agreeing verbs, and spatial verbs. Agreeing and spatial verbs use space to express agreement. According to Padden, the main difference between the two is that agreeing verbs inflect for person and number, with locations in space indicating subject and object. In contrast, spatial verbs make reference to locations: that is, to the initial and final location of the entity being moved or to the location where an entity is. Plain verbs differ from both agreeing and spatial verbs in that the sign does not inflect for its arguments (cf. Mathur \& Rathmann 2012 for an overview of several theoretical approaches to sign language agreement).

As for three-argument predicates, two options are possible. On the one hand, verbs may mark agreement with subject and indirect object (leaving aside the marking for the direct object), as in 5a where the verb GIVE is articulated in its basic form (see Figure 1). On the other hand, verbs may be expressed with classifier predicates, which consist in morphologically complex signs where all three arguments are incorporated into a single sign ( 5 b, Figure 2). The direct object is instantiated by the handshape, while subject and indirect object are instantiated by the initial and the final points of the movement path (as in the neutral form of the verb) (see Geraci \& Quer 2014 for an overview of existing analyses of argument structure in sign languages).

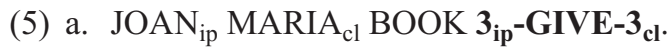

'Joan gave a book to Maria.'

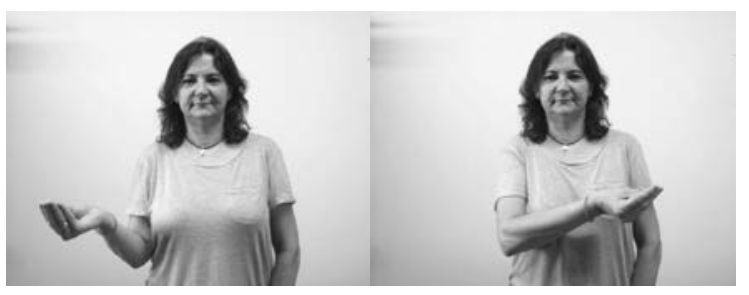

FIGURE 1. Verb GIVE instantiated by its basic articulation form. 
b. JOAN $_{\text {ip }}$ MARIA $_{\mathrm{cl}}$ BOOK $\mathbf{3}_{\text {ip }}-\mathbf{C L}_{\text {hand }}$.give- $\mathbf{3}_{\mathrm{cl}}$.

'Joan gave a book to Maria.'

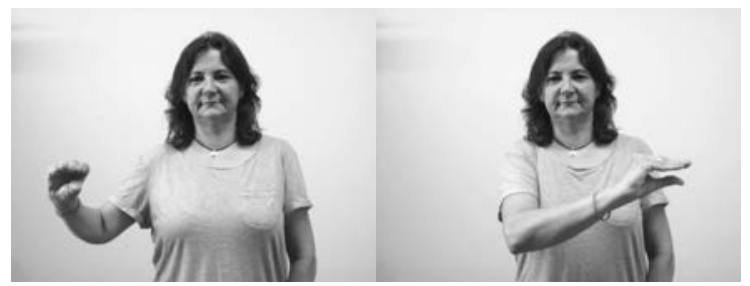

FIGURE 2. Verb GIVE instantiated by a classifier handshape.

Classifiers are morphemes with an underspecified meaning. They are expressed by particular hand configurations and represent entities by denoting salient characteristics (Zwitserlood 2012). They occur in combination with verbs, specifically verbs that indicate: (i) a referent's motion through space and its location and existence in space (ENTITY classifiers), or (ii) the handling of referents (HANDLING classifiers). While handling classifiers are considered to be transitive verbs, with an internal and an external argument instantiated in the handshape, entity classifiers correspond to intransitive unaccusative verbs, with one single internal argument only (Benedicto \& Brentari 2004).

The examples below show the contrast in handshape between entity and handling classifiers. The instantiation of the intransitive verb OPEN in example 6 is shown in Figure $3 \mathrm{~b}$ with an entity classifier expressed with a flat handshape. The instantiation of the transitive verb OPEN in example 7 is shown in Figure $4 \mathrm{~b}$ with a handling classifier expressed with a fist handshape.

(6) DOOR $\mathrm{CL}_{\mathrm{ent}}$.door-open.

'The door opened.'

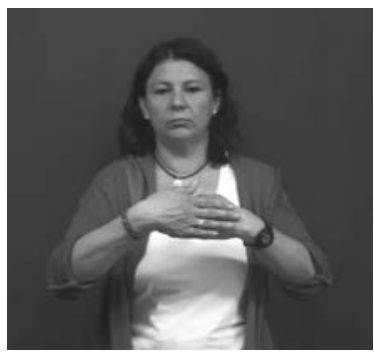

a. Lexical sign for 'door'.

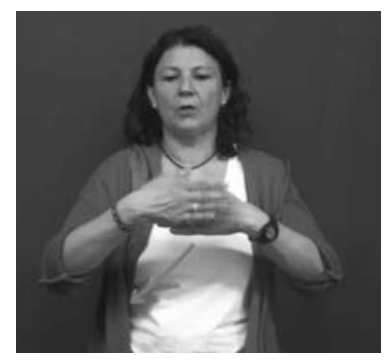

b. Entity classifier for 'door open'.

FIGURE 3. Instance of entity classifier.

(7) DOOR $\mathrm{CL}_{\text {hand }}$.door-open.

'Someone/They opened the door.'

For the case of LSC, it has been shown that the frontal plane, which extends parallel to the signer's body from the waist upward, is used to express specificity distinctions (Barberà 2012). DPs localized at a low locus are interpreted as specific (they are identifiable by the signer and belong to a restricted set), whereas DPs localized at a high locus are interpreted as nonspecific (they are unidentifiable by the signer and do not belong to a restricted set). In DPs containing a determiner, the place of articulation of the determiner determines the locus of the overall DP. When the DP does not contain a manual determiner, nonmanual markers such as direction of eyegaze or tilt toward a spatial 

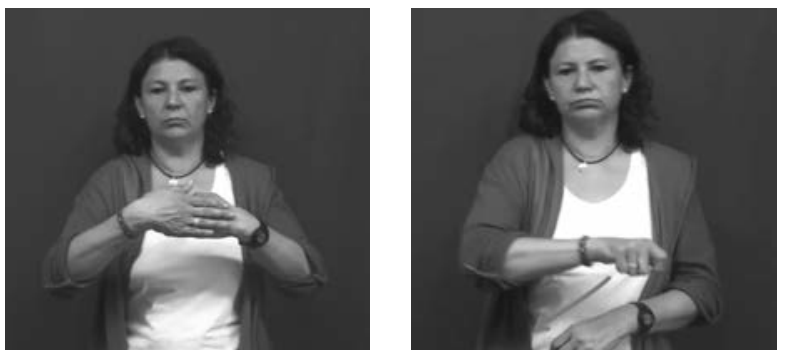

a. Lexical sign for 'door'.

b. Handling classifier for 'open door'.

FIGURE 4. Instance of handling classifier.

locus suffice to establish the locus (as described in Baker-Shenk \& Cokely 1980 for ASL). The following examples provide a minimal pair for the interpretation of high vs. low locus for a DP. In 8 a the determiner SOME is localized at a low locus (indicated in the glosses with $l o$; Figure 5) and corresponds to a reading where the signer is talking about a specific group of students, which he can identify. This contrasts with $8 \mathrm{~b}$ where SOME is localized at a high locus (Figure 6) and corresponds to a nonspecific reading, where the signer does not identify the set of students.

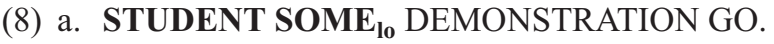

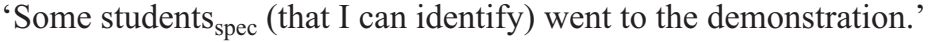

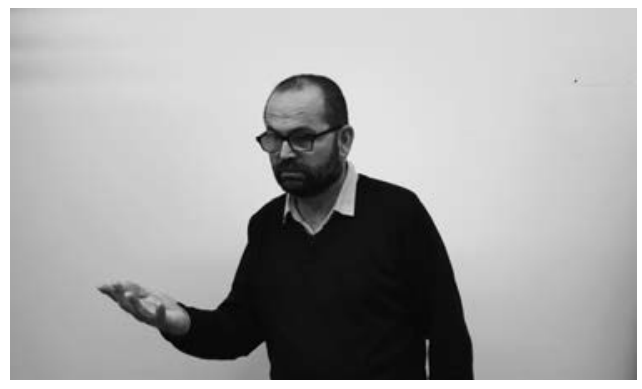

FIGURE 5. Determiner SOME localized at a low locus.

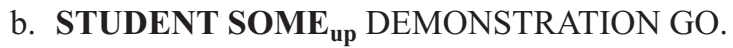

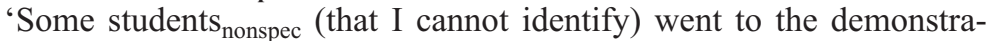
tion.'

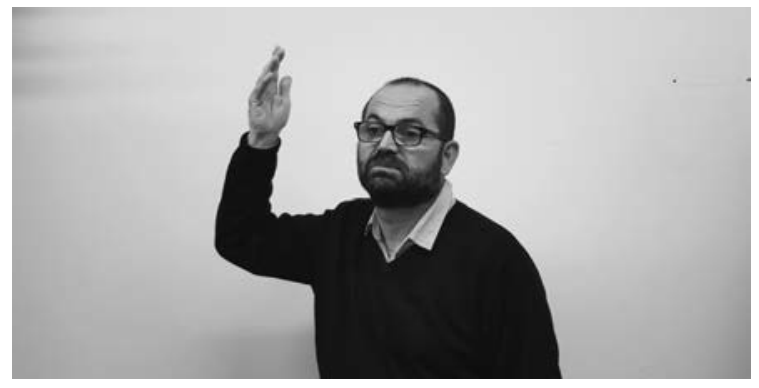

FIGURE 6. Determiner SOME localized at a high locus.

Examples 9a,b contrast a (necessarily specific) proper name with a nonspecific indefinite pronoun. The DP corresponding to the proper noun is localized at a low locus 
(9a), while the nonspecific indefinite pronoun $\mathrm{WHO}^{\wedge} \mathrm{IX} 3 \mathrm{pl}_{\text {up }}$ 'someone' is associated with a high locus (9b). Notice that in both cases verb inflection with the backward agreeing verb STEAL is with the locus of the subject, but at different heights: in 9a it agrees with a low locus, while in $9 \mathrm{~b}$ with a high locus.

(9) a. JOANA lo.ip MONEY STEAL-3 $_{\text {lo.ip. }}$

(proper name)

'Joana stole the money.'

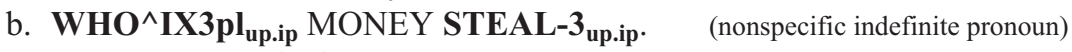

'Someone stole the money.'

Finally, sign languages have a variety of means to report the words, thoughts, and actions of others. ROLE SHIFT is a grammatical phenomenon whereby signers may shift into the role of a character, conveying information from that character's perspective (Lillo-Martin 2012). Under role shift, the signer's body or head position, for example, contributes to the marking of the point of view of a character of the story. This shift is indicated by a combination of nonmanuals, including change in the position of the signer's body, head, or shoulders, change in eyegaze direction, and change in facial expression, as shown in Figure 7 (Engberg-Pedersen 1993, Quer 2011).

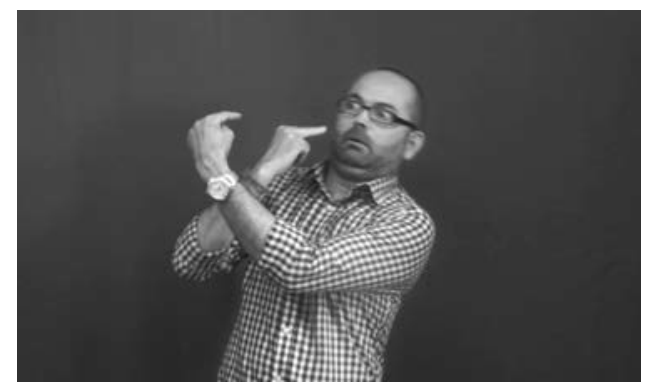

FIGURE 7. Instantiation of role shift.

3. Previous studies of agent backgrounding in Sign LANGuages. Previous studies have analyzed a number of different agent-backgrounding structures in sign languages. For ASL, Kegl (1990) analyzes the structure illustrated in 10 as a passive, taking the use of handling classifiers and role shift to be key features of the structure (Kegl 1990:166).

(10) POLICEMAN AT-HIT.

(ASL; Kegl 1990:166)

'The policeman got hit.'

Kegl argues that the verb in 10 is detransitivized: the form AT-HIT ${ }^{2}$ is articulated with the final configuration of the sign at the signer's body, with role shift to the patient of the verb, while at the same time the locus associated with the subject disappears. This contrasts with the basic transitive use of HIT in 11, in which the verb is articulated with path movement from the locus associated with the subject THIEF toward the locus associated with the object POLICEMAN. ${ }^{3}$

(11) POLICEMAN THIEF $_{\mathrm{cl}} 3_{\mathrm{cl}}-\mathrm{HIT}-3_{\mathrm{ip}}$.

'The thief hit the policeman.'

According to Kegl's description, the construction exemplified in 10 contains a single spatial location associated with the object of the verb and lacks any path movement: the

\footnotetext{
${ }^{2}$ See Kegl 1990 for details on her notational conventions.

${ }^{3}$ Examples taken from the literature have been adapted to our own notation system, as presented in $\mathrm{n} .1$.
} 
form is articulated entirely at the final object location. As there is role shift to the object argument, the articulating hands are directed toward the body of the signer, with a reduced movement path close to the body. According to Kegl's analysis, this final movement close to the signer is not due to agreement with a subject locus, as in the basic transitive use in 11, but is a residual movement due to the articulation of the verb itself.

Following up on Kegl's study, Janzen and colleagues (2001:288) examine agent backgrounding in ASL. These authors explicitly adopt a semantic definition of transitivity, taking weakly referential subjects to correspond to a reduction in (semantic) transitivity. Consequently, they consider sentences with subjects like 'someone' or a semantically empty subject locus to be passives, since the subject is backgrounded. This definition of PASSIVE is therefore independent of the SYNTACTIC properties of the grammatical subject. Janzen and colleagues take the prototypical passive in ASL to be characterized by the following properties (2001:288-90). First, the signer presents the clause from the point of view of the patient. In a transitive construction the point of view is that of the agent, while in the passive the signer shifts to the role of the patient and the agreement is marked with the final locus of the verb movement on the body of the signer, implying a shift in perspective toward the patient argument. Second, the agent is demoted, in one of two ways: (i) either the agent is expressed by a DP that is low in referentiality, expressed with the signs SOMEONE or WHO ('someone'), or (ii) no lexical agent is specified, and the movement of the agreeing verb begins at a morphosyntactic, but semantically empty, locus. An example of agent demotion by a DP with low referentiality is given in 12, with the particle WHO functioning as an indefinite pronoun. Agent demotion with an empty locus for the subject is illustrated in example 13. The movement of transitive verbs still begins at a morphosyntactically marked locus (indicated by subscript $c l$ on the glosses); however, this locus is not associated with any previous semantic content.

(12) WHO ip APPROACH-1, CLERC, 1-LOOK-AT ip FIRST DEAF TEACHER. 'Clerc was approached by someone; he was the first Deaf teacher.'

(13) ${ }_{\mathrm{cl}}$ GIVE-1 TROPHY.

'We were given the trophy.'

(ASL; Janzen et al. 2001:303, ex. 12)

(ASL; Janzen et al. 2001:293, ex. 6)

For Janzen and colleagues (2001), the empty agent locus in passive constructions is overtly marked as the starting point of the agreement movement at a marked spatial location, but it is semantically unfilled since no agent is previously specified. According to this description, the movement of the verb in 13 is not reduced (in contrast with the structures like 10 studied by Kegl); the verb is therefore not syntactically detransitivized, since a distal locus is overtly specified (if semantically empty).

Saeed and Leeson (1999) focus their analysis on Irish Sign Language (ISL) and identify two strategies for demotion of the agent. Dемотіon 1 is the more frequent type and is limited to agreeing verbs. The locus for the agent is established at a syntactically marked but semantically empty locus (indicated in the glosses with ip for ipsilateral), and the sign is articulated toward the locus for the patient (1999:14), as illustrated in 14 below. In this example the locus for the agent of STARE has not been established, and therefore a nonspecified human entity is implied.

(14) ${ }_{\text {ip }}$ STARE $_{\mathrm{c}}$.

'Someone was staring at me.'

(ISL; Saeed \& Leeson 1999:15, ex. 13)

Like Janzen and colleagues (2001), Saeed and Leeson (1999) discuss examples where the movement path of the agreeing verb establishes a subject at a higher location 
in signing space. For example, in a backward verb like TAKE (interpreted as 'takefrom'), the form is articulated with an onset point at the locus established for the bag, and an offset point at a higher plane in signing space.

(15) $\mathrm{BAG}_{\mathrm{c} \text { c }} \mathrm{TAKE}_{\text {up. }}$.

'The bag was stolen.'

(demotion 1, ISL; Saeed \& Leeson 1999:16, ex. 14c)

In demotion 1 structures, eyegaze plays an important role in conveying perspective. Averted eyegaze of the signer toward a lateral location indicates role shift, with the signer taking the role of the patient. When eyegaze is directed toward the addressee or toward a particular location, it indicates that the signer assumes the role of the agent. Saeed and Leeson conclude that averted eyegaze marks lack of involvement in the event and lack of intentionality (1999:18).

Saeed and Leeson also describe a second kind of detransitivization they call DEMOTION 2. This structure is characterized by the use of canonical space (neutral central signing space) as the nonspecified agent locus for agreeing verbs (Saeed \& Leeson 1999:23). This neutral central location seems to be serving as a default location for agent-type action, and it is clear that the signer is not the actor (1999:25).

(16) JAR SAME AGAIN 1-TAKE[move to c].

'Those same jars can be taken down again.'

(demotion 2, ISL; Saeed \& Leeson 1999:23)

Finally, Saeed and Leeson also present a third facet of detransitivization, which they term PROMOTION OF THE UNDERGOER. This strategy, which mainly cooccurs with demotion 1, arises when the signer's body functions as the undergoer. In example 17 the promotion of the undergoer is expressed with the palm orientation toward the signer, this being the opposite of the sign's citation form. Averted eyegaze also plays a role in undergoer promotion, showing lack of intention or awareness on the part of the undergoer, as also seen in demotion 1 structures (Saeed \& Leeson 1999:29).

(17) ME BEFORE-BEFORE BEAT-UP . $^{\text {. }}$

(ISL; Saeed \& Leeson 1999:28)

'I was beaten up.'

The two demotion strategies described by Saeed and Leeson clearly differ with respect to the locus of the unspecified actor (a high locus in demotion 1 and a central locus in demotion 2). Both demotion strategies cooccur with averted eyegaze. Both demotion 1 and demotion 2 involve a shift to the perspective of the undergoer for animate patients, while this shift is not necessary for inanimate undergoers (Saeed \& Leeson 1999:22).

Role shift and articulation in a neutral locus are also observed in studies of agent backgrounding in other sign languages. In his study of French Sign Language (langue des signes française, LSF), Guitteny (2006:311) identifies two strategies of agent demotion for transitive verbs, which resemble Saeed and Leeson's demotion 1 and 2: one structure with role shift of the signer to the undergoer, and a second structure without role shift and articulation of the sign from a neutral locus to the locus specified for the undergoer. For German Sign Language (Deutsche Gebärdensprache, DGS), Hansen (2007) explicitly argues that this language does not have a (syntactic) passive. Like the preceding studies, however, she identifies role shift and averted eyegaze as marking a backgrounded agent with two animate arguments.

Following up on the studies by Kegl (1990) and Janzen and colleagues (2001), Sze (2010) notes that these authors consider argument reduction for agreeing verbs using examples that typically include animate subjects and objects. In her study of Hong Kong Sign Language (HKSL), Sze (2010) therefore examines argument backgrounding 
with inanimate patients for both plain verbs and agreeing verbs. Based on data from an elicitation task, Sze concludes that agreeing verbs with animate patients differ from examples with inanimate patients in HKSL. For animate patients the signer shifts to the role of the patient, while for inanimate patients the difference between an indefinite subject and an agentless structure is marked on the classifier. If the clause contains an agent (mostly expressed with the indefinite pronoun SOMEONE), there is a strong tendency for the handling-classifier predicate to begin with a grasping action followed immediately by the predicate movement, as in 18. For agentless handling-classifier predicates, in contrast, there is no such grasping action and the movement path tends to be shorter, as in 19.

(18) SOMEONE $\mathrm{CL}_{\text {hand }}$.grasp-and-move-food-tray.

'Someone moved the tray.'

(HKSL; Sze 2010, ex. 2a)

(19) $\mathrm{CL}_{\text {hand }}$ move-food-tray.

'The food tray was moved.'

(HKSL; Sze 2010, ex. 2b)

Sze notes that the agentless construction in HKSL is heavily constrained. First, 'the agent must not be known or seen'-if the agent can be seen in the pictures used for elicitation, signers use SOMEONE to express the agent. Second, the interpretation in which the signer is the agent has to be clearly excluded by nonmanual marking and contextual clues. Sze further points out that examples with inanimate patients often occur with a resultative marker glossed as FINISH or ALL-DONE, as in 20a,b.

(20) a. IX-that T-SHIRT WRING FINISH.

(HKSL; Sze 2010, ex. 4/5)

'That T-shirt was wrung out.'

b. IX-that (bicycle) REPAIR ALL-DONE.

'That bicycle was repaired well.'

The studies discussed here examine a range of properties that play a role in agentbackgrounding constructions. Table 1 summarizes the subset of properties taken to be definitional of agent backgrounding in the different investigations.

\begin{tabular}{|c|c|c|c|c|c|c|c|}
\hline & ASL1 ASL2 & & & $\mathrm{L}$ & & & \\
\hline $\begin{array}{l}\text { Syntactically marked locus } \\
\text { (semantically empty)- } \\
\text { agreeing verbs }\end{array}$ & + & $\begin{array}{c}\text { DEM1 } \\
+\end{array}$ & $\begin{array}{c}\text { DEM2 } \\
+\end{array}$ & CON1 & $\begin{array}{c}\mathrm{CON} 2 \\
+\end{array}$ & ANIM & INAN \\
\hline Use of central neutral space & & & + & & + & & \\
\hline Role shift & + & $\begin{array}{l}+(\mathrm{w} / \\
\text { anim })\end{array}$ & $\begin{array}{l}+(\mathrm{w} / \\
\text { anim) }\end{array}$ & + & & + & - \\
\hline Averted eyegaze & & + & + & + & & + & \\
\hline High location of agent & + & + & - & & & $-?$ & - \\
\hline Distance from body & + & & & & & & \\
\hline Perfective marker & & & & & & & $\begin{array}{l}+ \text { (for } \\
\text { ctivities) }\end{array}$ \\
\hline
\end{tabular}

TABLE 1. Characteristic properties of agent-backgrounding constructions. Key: ASL1: Keg1 1990; ASL2: Janzen et al. 2001; ISL: Saeed \& Leeson 1999 (dem1: demotion 1, dem2: demotion 2), LSF: Guitteny 2006 (con1: construction 1, con2: construction 2), HKSL: Sze 2010 (anim: animate, inan: inanimate).

Taking into account the whole range of properties presented above, we show in $\S 5$ that LSC has at least two syntactically and semantically distinct agent-backgrounding constructions: the high-locus construction and the nonagreeing central construction, as introduced in $\S 1$ above. Before we develop our proposal, we briefly review the char- 
acteristic properties we use to distinguish between passives, R-impersonal subjects, and middles.

4. AgENT-BACKGROUNDING OPERATIONS: PASSIVES, R-IMPERSONAL SUBJECTS, AND MIDDLES. Agent backgrounding is a semantic notion that may be expressed by a range of syntactic constructions, including passives and R-impersonal subjects. We adopt the definition of passives from Keenan and Dryer (2007:328-29), according to which passives reduce the valency of the underlying predicate by suppressing one of the arguments and include an implicit agent as part of their interpretation. ${ }^{4}$

(21) a. Passive is a way of deriving n-place predicates from $n+1$-place predicates. (Keenan \& Dryer 2007:345)

b. A passivized predicate entails the existence of an agent. (Keenan \& Dryer 2007:352)

Following Siewierska (2011), we define R-impersonal pronouns as pronominal subjects of R(eference)-impersonals.

(22) R(eference)-impersonals are impersonals triggered by a reduction in referentiality. R-impersonals have the appearance of regular, personal constructions but feature a subject that is human and non-referential. The non-referential human subject may be expressed lexically, pronominally, or by the whole construction. (Siewierska 2011:57)

Syntactically, in prototypical passives the underlying verb is intransitivized, while R-impersonal subjects do not change the syntactic valence on the verb. R-impersonal subjects are exemplified by impersonal subject pronouns, such as French on in 23a, or antecedentless readings of third plural pronouns, such as they in the English translation. Example 23b exemplifies the copula passive in French, which suppresses the syntactic realization of the agent argument.

(23) a. On a volé mes vélos. on has stolen my bikes

'They stole my bikes.'

b. Mes vélos ont été volés.

(French; passive) my bikes have been stolen

'My bikes have been stolen.'

In 23a, the impersonal subject pronoun on shows the characteristic properties of a subject of a transitive sentence: on occupies the same slot as other subject clitics and triggers third singular agreement on the auxiliary $a$ 'has'. At the same time, the DP mes vélos 'my bikes' is in direct object position following the verb and can be replaced by an accusative clitic les (PRON.ACC.3PL). In 23b, the syntactic object has been promoted to syntactic subject: the DP mes vélos 'my bikes' precedes the verb, can be replaced by the subject pronoun ils 'they', and triggers third plural agreement on the auxiliary ont (and agreement on the participle). Notice that the majority of the syntactic diagnostics distinguishing sentences with R-impersonal subjects from sentences with a passivized predicate bear on the lexical DP corresponding to the patient. With intransitive verbswhich lack such a DP - it is therefore not always clear if an agent-backgrounding construction like 24 is to be analyzed as a transitive construction with an impersonal subject, as in $25 \mathrm{a}$, or as a passive with a suppressed agent argument, as in $25 \mathrm{~b}$.

\footnotetext{
${ }^{4}$ Keenan and Dryer (2007:328-29) point out that the most widespread type of passives (their 'basic passive') is agentless. Crosslinguistically, many passive constructions do not allow the demoted agent to be expressed as an oblique DP (Keenan \& Dryer 2007:331).
} 
(24) Aquí se trabaja mucho.

(Spanish) here REFL work.PRS.3sG a.lot

'Here a lot of work is done./Here people work a lot.'

(25) a. Hier arbeitet man viel. here work.PRS.3SG INDEF a.lot

(German; R-impersonal subject)

'Here people work a lot.'
b. Hier wird
viel gearbeitet.
(German; impersonal passive)

here AUX.PASS.PRS.3sG a.lot worked

'Here a lot of working is done.'

This ambiguity between R-impersonal subjects and passives also arises for sign languages. For French Sign Language (LSF), Guitteny (2006) proposes to analyze agreeing verbs with a neutral actor locus as passives, in contrast with Cuxac (2000:199), who analyzes this type of construction as the equivalent of the R-impersonal subject pronoun on in French. ${ }^{5}$

Syntactic analyses of the passive differ with respect to the syntactic representation assigned to the demoted subject. Some analyses take the demoted agent to be represented in the syntactic structure (Jaeggli 1986, Baker et al. 1989), while others take the argument reduction of passives to be presyntactic and consequently do not have an element corresponding to the agent in the syntax (Chomsky 1981, Perlmutter \& Postal 1984, Dobrovie-Sorin 1998).

Passives and R-impersonals differ semantically in the range of interpretations available for the backgrounded agent. Many passives can have animate and inanimate implicit agents, as in 26a, while R-impersonal pronouns are limited to human interpretation, as in $26 \mathrm{~b}$.

(26) a. Passive

The window was opened (by the woman/by the wind).

b. R-impersonal subjects

i. Lexical impersonal pronoun

On a ouvert la fenêtre.

(French; human agent only)

ON has opened the window

'Someone opened the window.'

ii. Impersonal use of third plural pronoun

They opened the window.

(English; human agent only)

Since some passive constructions are also limited to human implicit agents (e.g. the Icelandic vera-passive and the Romance reflexive passive), it is only the possibility of nonhuman implicit agents that is informative: if an agent-backgrounding construction allows implicit nonhuman agents and causes, this suggests that it does not involve an R-impersonal subject.

We further distinguish passives from middles. While passives have an implicit agent, middles reduce valency without requiring an implicit agent, thus allowing anticausative and nonagentive readings (Keenan \& Dryer 2007:352-53). ${ }^{6}$

\footnotetext{
${ }^{5}$ Cuxac (2000:199) claims that ' $[o] n$ has a corresponding form in LSF, namely to make the movement of the verb INFORM start from a neutral locus that is independent of the presence of a concrete person' (cited in Guitteny 2006:312).

${ }^{6}$ In the literature, the term middle is not defined uniformly. The term middle voice originates in the Ancient Greek grammatical tradition, used for the nonactive verb form that allowed passive, anticausative, reflexive, reciprocal, and auto-benefactive interpretations (Kulikov 2013:274). Ancient Greek middle verb forms are nonactive verb forms that do not necessarily imply an agent but have a grammatical subject that is affected by the event. The exact range of meanings of the middle form varies across languages (Kulikov 2013:273). The
} 
(27) Unaccusative open: middle semantics
a. No cause
The window opened spontaneously.
b. Underspecified cause
The window opened.
[felicitous continuations: John/The wind/A branch knocked it open.]

In what follows, we use the properties listed in Table 2 to distinguish between R-impersonal subjects, middles, and passives. ${ }^{7}$

\begin{tabular}{|c|c|c|c|}
\hline & $\begin{array}{l}\text { R-IMPERSONAL } \\
\text { SUBJECT }\end{array}$ & MIDDLE VERB & $\begin{array}{c}\text { PROMOTIONAL } \\
\text { PASSIVE }\end{array}$ \\
\hline $\begin{array}{l}\text { SYNTAX } \\
\text { transitivity } \\
\text { patient DP }\end{array}$ & $\begin{array}{l}\text { unchanged } \\
\text { grammatical object } \\
\text { properties }\end{array}$ & $\begin{array}{l}\text { argument reduction } \\
\text { grammatical subject } \\
\text { properties }\end{array}$ & $\begin{array}{l}\text { argument reduction } \\
\text { grammatical subject } \\
\text { properties }\end{array}$ \\
\hline $\begin{array}{l}\text { SEMANTICS } \\
\text { implicit agent obligatory } \\
\text { unexpressed agent can be } \\
\text { natural cause or inanimate } \\
\text { (continuations) }\end{array}$ & $\begin{array}{l}\text { yes } \\
\text { no }\end{array}$ & $\begin{array}{l}\text { no } \\
\text { agentivity not necessary; } \\
\text { continuations with } \\
\text { natural cause/ } \\
\text { inanimate cause } \\
\text { possible }\end{array}$ & $\begin{array}{l}\text { yes } \\
\text { yes/no (depending on } \\
\text { the passive) }\end{array}$ \\
\hline
\end{tabular}

TABLE 2. Diagnostics distinguishing R-impersonal subjects, middles, and passives.

Notice that the distinction between transitive sentences with an R-impersonal subject, on the one hand, and intransitivized passives and middles, on the other, is syntactic. In contrast, the distinction between passives and middles is semantic, as it depends on the range of available readings. With the distinction between passives, middles, and R-impersonal subjects outlined here as a backdrop, we now turn to the syntactic and semantic properties of two agent-backgrounding constructions in LSC.

5. Two AGENT-BACKGROUNDING CONSTRUCTIONS IN LSC. In our study of LSC we take into account the whole range of properties shown in Table 1. In what follows we provide evidence that for LSC at least two different agent-backgrounding structures have to be distinguished: the high-locus construction and the nonagreeing central construction. The high-locus construction is characterized by the following properties.

(28) High-locus construction:

a. agent is left unexpressed;

b. verb is inflected (agreeing verbs and plain verbs);

\footnotetext{
cognate verb form of the Ancient Greek middle voice in Sanskrit, for example, was mainly used for anticausative readings (Kulikov 2013:274). The Russian reflexive middle marked by -sja/-s' covers passive, anticausative, reflexive, and reciprocal interpretations (Kulikov 2013:273). For variation of the interpretation of reflexive-marked verbs in Romance, see Dobrovie-Sorin 2005. Other definitions of the term middle include an active form of the transitive verb with the patient in subject position and an implicit agent, as in the English This books reads easily (Keyser \& Roeper 1984), while yet another use of the term middle refers to the stative property use with an implicit agent, independently of whether or not the verb is morphologically marked or identical to the active form (see e.g. Ackema \& Schoorlemmer 2005).

${ }^{7}$ See Keenan \& Dryer 2007 for a detailed discussion of agent-reducing devices, Blevins 2003 for the distinction between passive verbs and impersonal verb forms, and Cabredo Hofherr 2017 for the distinction between passive verbs, impersonal verb forms, and impersonal subjects.
} 
c. agreement between a high locus for the agent argument that has not been previously activated and

i. the body of the signer, which functions as the patient (with animate patients), or

ii. neutral signing space (with inanimate patients);

d. with animate patients: role shift of the signer to the patient, marked by averted eyegaze and body lean.

This construction shares properties with the one considered in Kegl 1990, the agentless construction in Janzen et al. 2001, and demotion 1 combined with promotion of the undergoer in Saeed \& Leeson 1999. An example in LSC is provided in 29, adapted from the ASL example in 10 above, taken from Kegl 1990.

averted eyegaze/body lean

(29) POLICEMAN 3 up -HIT-1. rs:police

'They/Somebody hit the policeman.'

The nonagreeing central construction in LSC is characterized by the properties listed in 30 , and it is exemplified in $31 .^{8}$

(30) Nonagreeing central construction:

a. the agent is left unexpressed;

b. the verb is not inflected;

c. inanimate patient;

d. the sign is articulated in neutral space in front of the signer;

e. often followed by the perfective marker ALREADY.

(31) HOUSE BUY $\mathbf{c}$ ALREADY.

'The house was bought.'

For LSC the high-locus construction and the nonagreeing central construction represent two distinct constructions, as shown by the minimal pair in 32 and 33 involving the same predicate BREAK. Example 32 is an instance of the nonagreeing construction. This example shows the default articulation of plain verbs in neutral signing space (in front of the chest of the signer, and indicated in the glosses with $c$ ), without movement between locations for agent and patient (Figure 8). In 32 there is no previously introduced lexical sign that would correspond to an agent of the event. The central articulation of the verb is often (but not obligatorily) followed by the resultative marker ALREADY. The uninflected default articulation of the plain verb in 32 contrasts with the inflected realization of the plain verb in 33. In the high-locus construction shown in 33 the plain verb BREAK is signed with the final hold at a lateral and high location in signing space (Figure 9). This articulation of the plain verb establishes a marked locus for the agent, yielding a univocally transitive predicate. As the locus for the agent has not been previously activated, this configuration is interpreted as agentive with a nonspecific human agent. The patient in 33 is inanimate, and therefore there is no role shift.

(32) POT FLOWER BREAK $\mathbf{K}_{\mathbf{c}}$ ALREADY.

'The flower pot broke.'

(33) POT FLOWER BREAK-3 up.

'They/Somebody broke the flower pot.'

(nonagreeing central construction)

(high-locus construction)

\footnotetext{
${ }^{8}$ Saeed and Leeson (1999:27) take central subject locus as a characteristic of demotion 2. However, the examples that the authors discuss in detail involve agreeing verbs, and it is not clear from the discussion whether they analyze agentless nonagreeing verbs articulated in the c-locus as instances of demotion 2.
} 


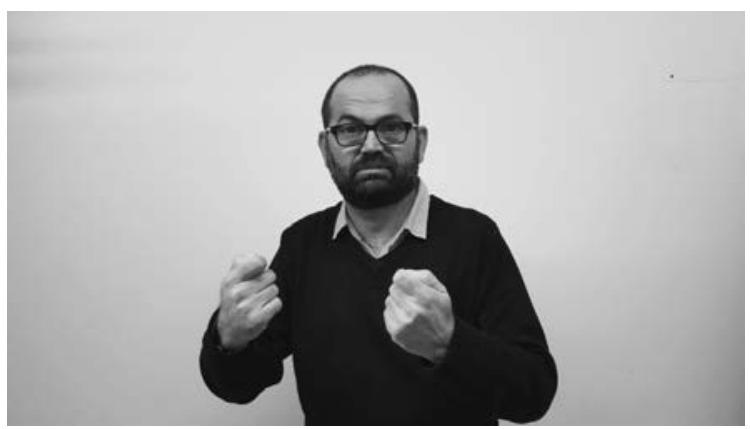

FIGURE 8. Nonagreeing construction instantiated by the uninflected plain verb BREAK.

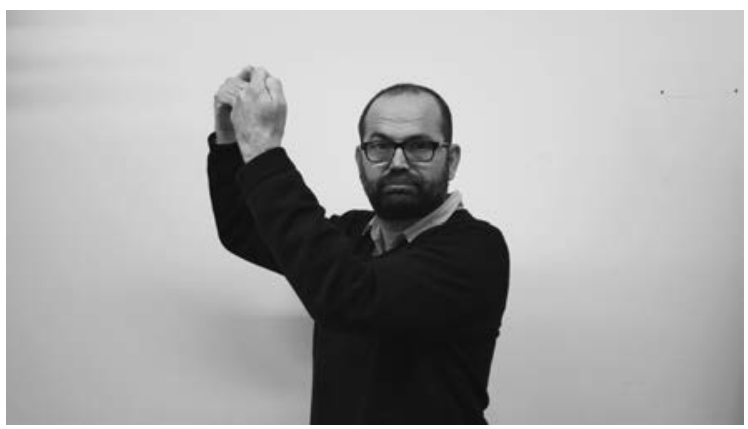

FIGURE 9. High-locus construction instantiated by the inflected plain verb BREAK.

The patient in the high-locus construction may be animate or inanimate. With animate patients, as in 34 , the verb agrees with the body of the signer, which takes on the role of the patient through role shift. With an inanimate patient, as in 35 and in 33 above, no role shift is found: the verb agrees with a neutral location established in the center of the signing space and with a high location established for the agent.

br

rs:maria

(34) MARIA MEETING PREPARE $3_{\text {ip.up }}$-SUMMON-1.

(animate patient with role shift)

'Maria was preparing for the meeting and they summoned her.' br

BIKE, ${ }_{c}$ STEAL- $3_{\text {up }}$.

'They/Somebody stole the bike.'

(inanimate patient without role shift)

The types of verbs found in each construction do not correspond to the lexical classification between agreeing and plain verbs (cf. Padden 1990 and $\$ 2$ above). While the high-locus construction may include both agreeing verbs and plain verbs with added inflection, the nonagreeing central construction is limited to plain verbs. In the minimal pair in 32 and 33, we have a plain verb with and without inflection. When plain verbs are inflected in the high-locus construction, as in 33 , the verb is articulated at the locus associated with the agent argument (see Costello 2016, Zwitserlood \& van Gijn 2006 for a discussion of single-argument agreement). Since articulation at the agent locus is used as agreement, the inflected plain verb only allows for agreement with one argument. The high-locus construction in LSC shows that single-argument agreement can take place even if the argument has not been previously activated.

In what follows we examine the syntactic and semantic properties of the two constructions. We show that the high-locus construction is interpreted as involving an im- 
plicit nonspecific human agent, while the nonagreeing central construction allows readings with animate and inanimate agents as well as agentless anticausative readings (§5.1). Using diagnostics for agentivity, we show that the nonagreeing central construction is compatible with an implicit agent on a par with the implicit agent of the high-locus construction (§5.2). Section 5.3 provides evidence that the high-locus construction is syntactically transitive. Finally, $\$ 5.4$ examines the factors that distinguish the two agentbackgrounding constructions from reflexives.

5.1. SORTAL RESTRICTIONS ON THE IMPLiCit AGENT. In the high-locus construction the backgrounded agent has to be interpreted as human. Consider example 33, repeated here as 36, in which the verb BREAK, which lacks path movement in its plain articulation, is articulated in a lateral and upper location, as shown in Fig. 9 above. Excluding topographical and contrastive interpretations of the high locus, ${ }^{9}$ an inflected form gives rise to an $\mathrm{R}$-impersonal interpretation with a human agent reading, as shown by the continuation in 36a. The continuations in 36b,c,d, which imply a dynamic, inanimate cause or an anticausative interpretation, are not felicitous with this example, as indicated with the hashtag \#.

(36) POT FLOWER BREAK-3 'They broke the pot.'

a. JOHN CLUMSY.

'John is clumsy.'

b. \#WIND STRONG.

'The wind is strong.'

c. \#WINDOW $\mathrm{CL}_{\text {ent }}$.open.

'The window opened.'

(high-locus construction)

d. \#ALONE.

'It happened spontaneously.'

(human agent)

(dynamic cause)

(inanimate cause)

(agentless)

According to our informants, interpretations $36 \mathrm{~b}, \mathrm{c}, \mathrm{d}$ are possible only if the context is derived from a topographic use of space in which the higher articulation of the verb reflects the mapping of the position of the object in space (in a high location to the left, for instance). When the use of signing space is not biased by the mapping of the actual position of the object in space, the interpretation is limited to a human agent (36a). ${ }^{10}$

The nonagreeing central construction, by contrast, is not limited to human agents. A transitive plain verb like BREAK in LSC is usually signed in neutral signing space (Fig. 8 above). This articulation is compatible with continuations involving human agents (37a), natural causes (37b) (which is the preferred reading, according to our informants), inanimate causes (37c), and agentless readings (37d).

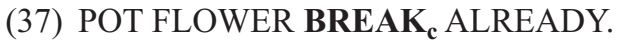

'The pot broke.'

a. JOHN CLUMSY.

(nonagreeing central construction)

'John is clumsy.'

\footnotetext{
${ }^{9}$ In sign languages signing space can be interpreted topographically or contrastively (Barberà 2012, Klima \& Bellugi 1979). In a topographical interpretation, a high locus is interpreted as a high location, as in 'The pot on the upper left shelf was broken'. In contrastive uses of space, placement can express contrast with another individual of the same type, as in 'That particular pot, not the other, was broken'. In LSC, contrastive spatial locations do not have access to high locations without a topographical use of space.

${ }^{10} \mathrm{~A}$ single locus may correspond to an abstract use of space and to a topographic one. In these contexts in LSC, the abstract use overrides the topographic one (see the discussion in Barberà 2012:Ch. 3).
} 
b. WIND STRONG.

(natural cause; preferred reading)

'The wind is strong.'

c. WINDOW CL $\mathrm{ent}_{\text {. open. }}$

(inanimate cause)

'The window opened.'

d. ALONE.

'It happened spontaneously.'

(agentless)

The examples above illustrate that in the high-locus construction the agent is obligatorily human and unspecified, while the nonagreeing central construction is compatible with backgrounded agents corresponding preferentially to a natural cause, but also allows inanimate and animate agents as well as agentless anticausative readings. Both constructions can appear with animate or inanimate patients. Table 3 summarizes the semantic restrictions for the agent and the patient in the two constructions.

\begin{tabular}{|c|c|c|}
\hline HIGH-LOCUS CONSTRUCTION & $\begin{array}{c}\text { AGENT } \\
\text { Human agent }\end{array}$ & $\begin{array}{l}\text { PATIENT } \\
\text { Animate (expressed with role shift) } \\
\text { Inanimate (articulated in neutral signing space) }\end{array}$ \\
\hline $\begin{array}{l}\text { NONAGREEING CENTRAL } \\
\text { CONSTRUCTION }\end{array}$ & $\begin{array}{l}\text { Natural cause } \\
\text { Inanimate cause } \\
\text { Human agent } \\
\text { Absent }\end{array}$ & $\begin{array}{l}\text { Animate } \\
\text { Inanimate }\end{array}$ \\
\hline
\end{tabular}

TABLE 3. Semantic restrictions on agent and patient in the two constructions.

5.2. Agentivity. In what follows we apply two tests in order to establish the presence of an agentive external argument: modification by an agent-oriented expression (like 'deliberately'), and compatibility with purpose clauses. ${ }^{11}$ We examine each of these in turn, and we show that the agent is semantically active in the high-locus construction. The nonagreeing central construction is compatible with expressions oriented toward a volitional agent, but agentive modification blocks the construction's otherwise preferred interpretation as involving a natural or inanimate cause.

ModificATION By AGENT-ORIENTED PARTICLES. Agent-oriented particles provide a test for the semantic presence of a volitional agent. The insertion of an agent-oriented particle such as WANT, translated as 'deliberately/on purpose', is a diagnostic for the

${ }^{11}$ We do not use classifiers as a test for argument structure in LSC. Previous literature on handling classifiers has shown that these complex structures incorporate an agentive external argument and an internal one (Benedicto \& Brentari 2004 for ASL; Benedicto, Cvejanov, \& Quer 2007 for LSC and Argentinian Sign Language). According to these authors, handling classifiers preserve a transitive structure (both subject and object are incorporated into the handshape), while entity classifiers are considered intransitive unaccusative structures (with a single internal argument). However, Zwitserlood (2012) argues that the type of classifier is predictive of argument structure only for verbs of motion and location, while for other verbs it is not reliably correlated with argument structure. In LSC both types of classifier are compatible with an agentive interpretation: the high-locus construction is compatible with modification by WANT with both types of classifier, showing that entity classifiers in LSC are compatible with implicit agents (and therefore not obligatorily interpreted as unaccusatives).
(i) a. TRAY up.jp $\mathbf{C L}_{\text {hand }}$ turn-over WANT.
b. TRAY up.ip $\mathbf{C L}_{\text {ent }} \cdot$ turn-over WANT.
'They turned over the tray on purpose.'
(handling classifier) (entity classifier)

In the nonagreeing central construction, however, in the absence of a syntactic locus for the agent, the choice of classifier disambiguates between an agentive and a nonagentive reading.

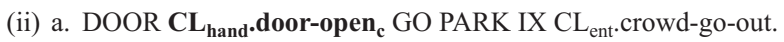
'They opened the door to go out to the park.'

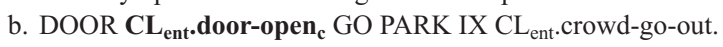

'The door opened and the people went out to the park.'

(handling classifier)

(entity classifier) 
presence of an intentional agent associated with the action. The agent-oriented particle can be freely combined with the high-locus construction, with the intention attributed to the implicit human agent, as shown by the felicitous continuation of 38 in $38 \mathrm{a}$. When WANT combines with the nonagreeing central construction, the only felicitous interpretation is the human agentive one (39a); as expected, agentive modification blocks the nonagentive interpretations $(39 \mathrm{~b}, \mathrm{c})$.

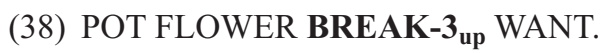

'They broke the pot on purpose.'

(high-locus construction)

a. PARTY KIDS MESS ATTITUDE BAD.

'The kids at the party behaved badly.'

(39) POT FLOWER BREAK $\mathbf{c}_{\mathbf{c}}$ WANT.

'The pot was broken on purpose.'

(nonagreeing central construction)
a. PARTY KIDS MESS ATTITUDE BAD.
'The kids at the party behaved badly.'
b. \#WIND STRONG.
'The wind is strong.'
c. \#WINDOW $\mathrm{CL}_{\text {ent }}$.open.
'The window opened.'

Continuation with Purpose Clauses. A continuation with a purpose clause implies the semantic presence of an intentional agentive argument involved in the event. In the inflected version with a high-locus construction (40), combining with the purpose clause attributes an intention to the agent of the breaking event. In the noninflected version (41), the purpose clause is also felicitous, showing that an interpretation with an implicit agent is possible. As in 39 above, the agentive modification blocks interpretations with natural and inanimate causes that are otherwise preferred for the nonagreeing central construction.

(40) PIGGY-BANK ip $_{\text {BREAK }}$ ip.up MONEY $3_{\text {ip.up-COLLECT-1. (high-locus c.) }}$ 'They broke the piggy-bank to collect the money.'

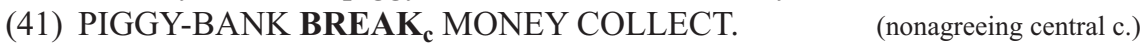
'The piggy-bank was broken to collect the money.'
a. IX3 $3_{\text {up }}$ MONEY NEED.
'They needed money.'
b. \#WINDOW CL $\mathrm{ent}_{\text {. open. }}$
'The window opened.'
c. \#WIND STRONG.
'The wind was strong.'

The data discussed in this section show that the nonagreeing construction allows an interpretation with a semantically active implicit volitional agent. In the high-locus construction, as expected, the obligatorily human implicit agent is compatible with agentive modification.

5.3. Transitivity. Several arguments show that the high-locus construction does not reduce transitivity of the underlying predicate. ${ }^{12}$ First, with an agreeing verb and with a

\footnotetext{
${ }^{12}$ LSC has no marking of grammatical relations. In contrast, Italian Sign Language (lingua dei segni italiana, LIS) marks grammatical relations using lateralization (Geraci 2014): controlling for topographical use of signing space, subjects are localized on the ipsilateral side, while objects are localized on the contralateral side. In previous work, we argue that lateralization provides further evidence that the LIS equivalent of the high-locus construction is transitive (Barberà \& Cabredo Hofherr 2016). In this construction, the lateral consistency is kept, suggesting that the construction does not involve syntactic promotion of the object to subject. The object is kept in the contralateral area, as evidenced by the path of the agreeing verb. When the sentence
} 
transitivized plain verb, a location for the agent of the clause is clearly established in a lateral and high location in signing space in LSC. ${ }^{13}$ The high locus, which in LSC triggers a nonspecific interpretation (Barberà 2012), contrasts with the low lateral locus associated with referential DPs. While 42 shows an instance of a sentence without a lexical agent and with an agreeing verb inflected for a high locus (see Figure 10), 43 is an instance of a referential subject and a low agreeing verb (see Figure 11).

(42) $3_{\text {up.ip }}$-SHOOT JOHN.

'They shot John.'

(high-locus construction)

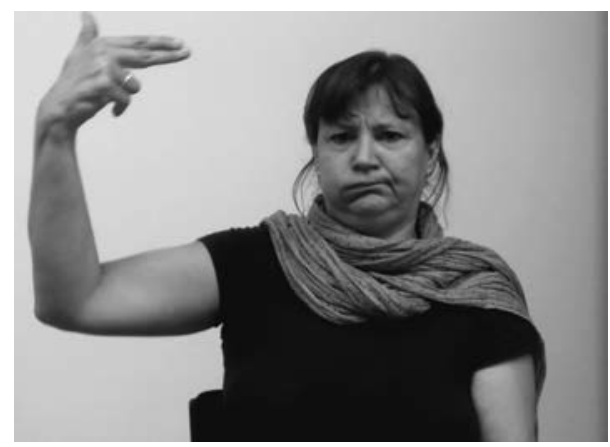

FIGURE 10. High locus for the agent of the predicate SHOOT.

(43) MARY JOHN $_{\mathrm{cl}} 3_{\text {ip.lo }}-$ SHOOT- $3_{\mathrm{cl}}$.

'Mary shot John.'

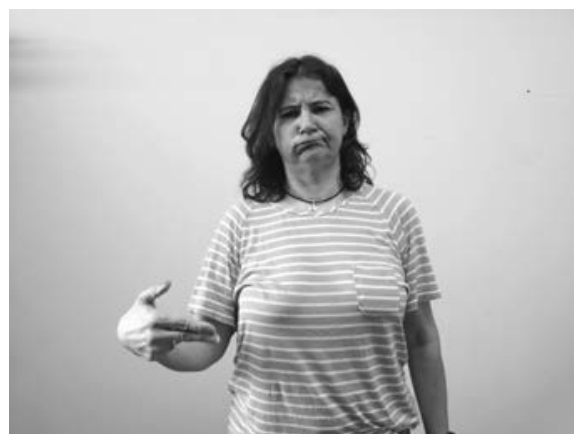

FIGURE 11. Low locus for the agent of the predicate SHOOT.

Second, there is evidence that in LSC the high locus is a distinctive locus and cannot be analyzed simply as the omission of an agent, with the starting point of the path movement assimilated from a previous sign outside of the referential signing space. We

is continued by a coreferential pronoun referring to the agent, the index pronoun is also directed to the ipsilateral side. For the nonagreeing construction in LIS, by contrast, the object is articulated in the center of the signing space without lateralization.

${ }^{13}$ Moreover, LSC allows the establishment of two different loci for the high agent, explicitly marking distribution over the subject (Barberà \& Cabredo Hofherr 2017). In a sentence like (i) the agreement verb STEAL is inflected with two high loci: one ipsilateral, one contralateral, and it results in a reading where the indefinite subject covaries with the stealing event, namely, 'there have been two times in which someone stole my bike'.

(i) $\mathrm{WHO}^{\wedge} \mathrm{SOME}_{\text {up }}$ IX1 POSS BIKE 1-STEAL-3 up.a $_{\text {1-STEAL-3 }}$ up.b TWO TIMES.

'They stole my bike two times.' (two times $>$ someone) 
can exclude the possibility of the high locus being a phonological assimilation to the location used for previous signs by inserting an adverb that is articulated at a lower locus. In example 44, the sign HERE has such an articulation: it is expressed at a lower and central location, as seen in Figure 12. Example 44 shows that though the adverb HERE precedes it, the verb SHOOT is not articulated at a low locus, as would be expected if there was agent omission and assimilation to the locus of the preceding sign. Instead, the sign for the predicate is articulated by going from the lower location in the center to the higher lateral location, therefore showing that the high locus is independently established in signing space. The sign for SHOOT in the high-locus construction keeps its transitive structure from the distinguished high agent locus to the object.

(44) MARIA HERE $3_{\text {up }}$-SHOOT-1.

'They shot Maria here.'

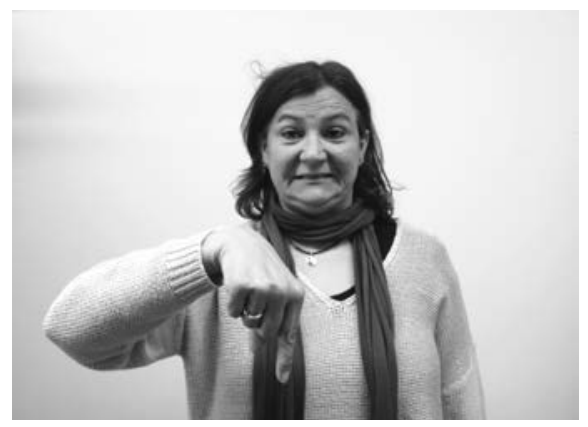

a. Sign HERE.

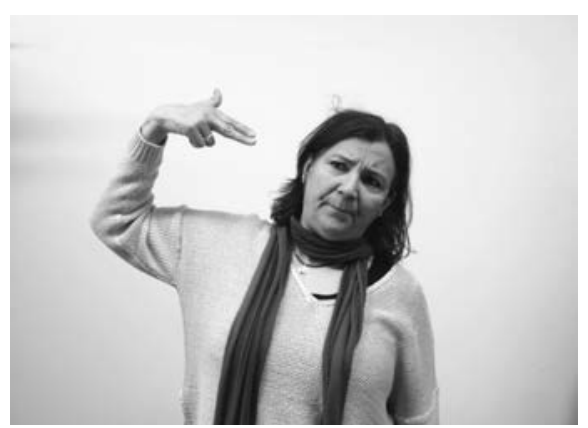

b. Sign $3_{\text {up }}$-SHOOT-1.

FIGURE 12. Central articulation for HERE and high lateral locus for SHOOT

In example 45, the empty agent of the high-locus construction is preceded by the adverb YESTERDAY, a sign that is articulated outside of the central signing space on the dominant shoulder. If the empty locus were the result of agent omission along with a nondistinct locus outside of the referential signing space, we would expect the place of articulation of the agent of SHOOT to be assimilated to the locus of the sign YESTERDAY. This is not what we find, however, as the high agent locus is established by going from the location at the shoulder to the higher location (Figure 13), showing again that the high locus is independently established in the high plane of the signing space.

(45) MARIA YESTERDAY 3 up-DRESS-1.

(high-locus construction) 'Yesterday, they dressed Maria.'

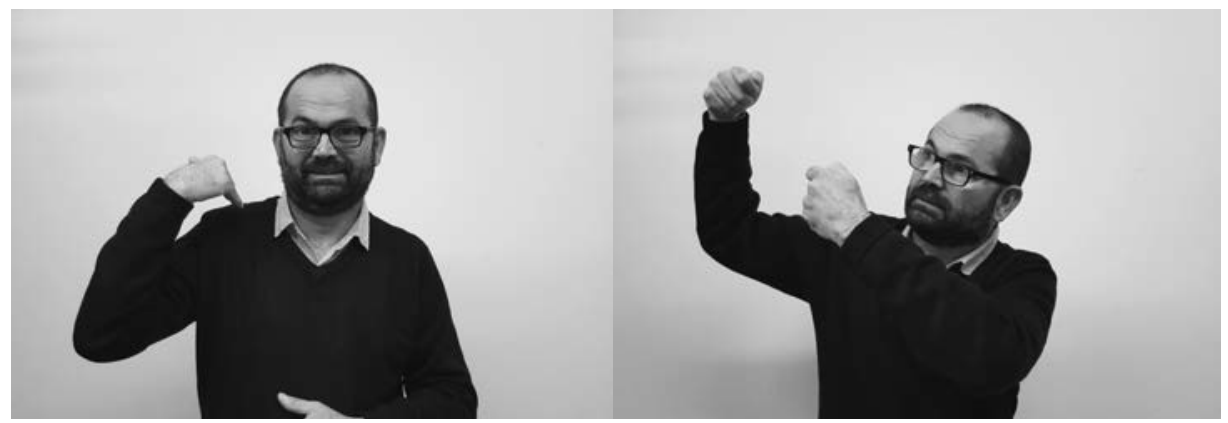

a. Sign YESTERDAY.

b. Sign $3_{\text {up }}$-DRESS.

FIGURE 13. Articulation with contact at the shoulder for YESTERDAY and high lateral locus for DRESS. 
For the nonagreeing construction, by contrast, there is no activation of a high locus. When preceded by a sign that has a lexical higher articulation, such as the sign MOUNTAIN in 46, the plain verb still keeps its articulation at a lower and central location in the signing space, as seen in Figure 14.

(46) HOUSE MOUNTAIN BUY ${ }_{\mathrm{c}}$ ALREADY.

(nonagreeing central construction)

'The house at the mountain was bought.'

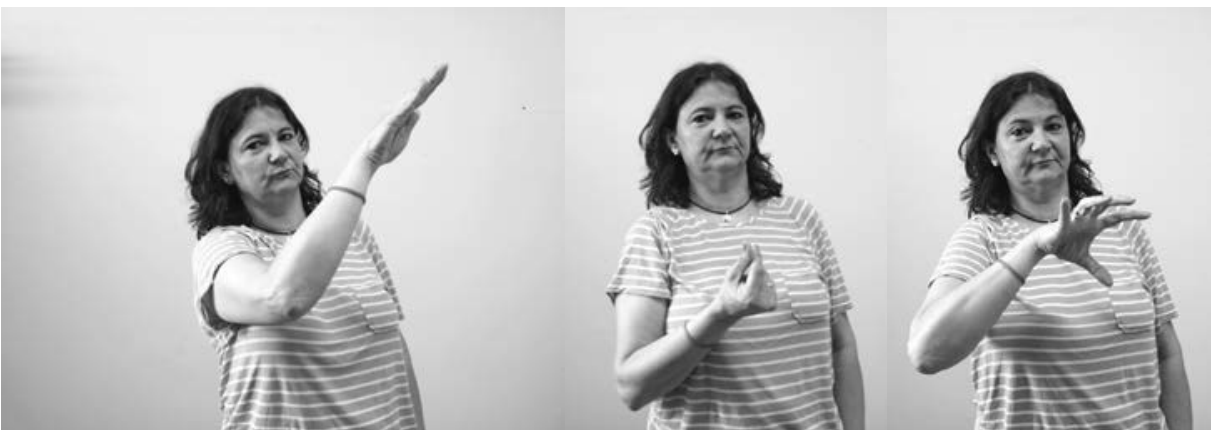

a. Sign MOUNTAIN

b. Sign BUY.

FIGURE 14. High articulation of preceding sign MOUNTAIN and central articulation of predicate BUY.

The last argument showing that the high-locus construction is a transitive structure comes from the possibility of inserting the auxiliary agreement sign, which in LSC has a trajectory movement that goes from the location established for the subject to that established for the object (Quadros \& Quer 2008, Steinbach \& Pfau 2007). When inserted into the high-locus construction, this agreement sign's trajectory moves from the empty high locus associated with the subject to the locus associated with the object. Moreover, the signer's eyegaze is also directed to this initial point, additionally activating the spatial location. While the agent argument is not previously introduced, high articulation and activation by the signer's eyegaze show that the unspecified argument has its own locus in space. In example 47 the final endpoint of the auxiliary agreement sign is on the body of the signer, which functions as the patient. As shown in 47, the agreeing verb moves from the ipsilateral to the contralateral area, and the auxiliary agreement sign follows the same path (see also Figure 15).

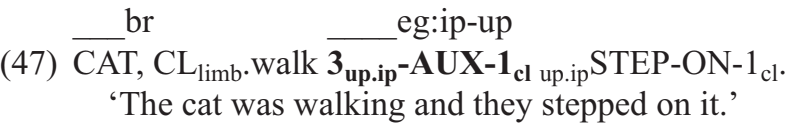

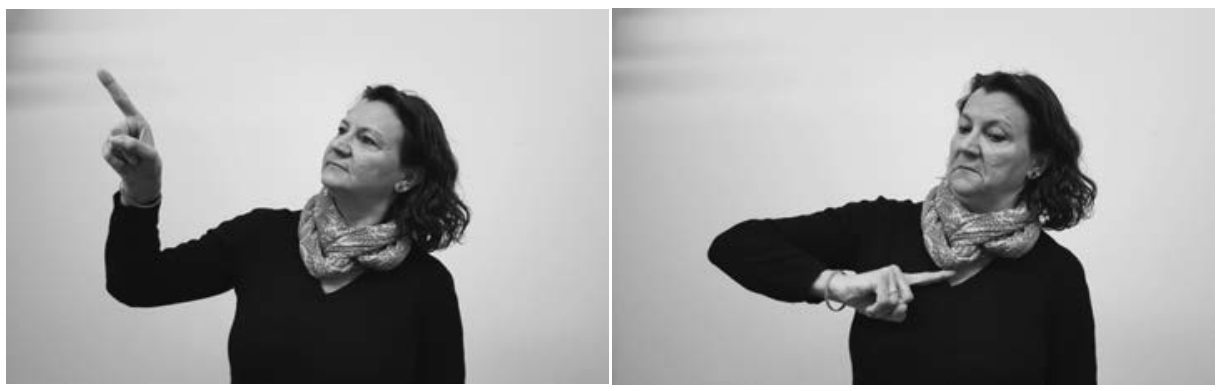

FIGURE 15. Auxiliary sign moving from high locus to the patient argument, coarticulated with eyegaze to the initial high locus. 
In the nonagreeing central construction, the insertion of the auxiliary agreement sign is felicitous only with an agentive interpretation, as in 48a. When the agreement sign is overtly expressed, the other possible interpretations of the construction are excluded, as in 48 b,c. Example 49 shows that the auxiliary agreement sign cannot be felicitously combined with the sign ALONE 'spontaneous', providing further evidence that the transitive structure contributed by the agreement sign forces an agentive interpretation.

(48) POT BREAK $\mathbf{3}_{\text {ip }}-\mathbf{A U X}-\mathbf{3}_{\mathbf{c}}$. 'The pot was broken.'

(nonagreeing central construction)

a. JOHN CLUMSY.

'John is such a clumsy guy.'

b. \#WINDOW $\mathrm{CL}_{\text {ent }}$.open.

'The window opened.'

c. \#WIND STRONG.

'The wind was strong.'

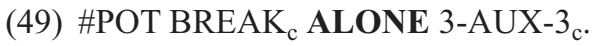

'The pot was broken spontaneously.'

5.4. COMPARING REFLEXIVES AND ARGUMENT REDUCTION IN LSC. As is well known, reflexives are a common source of agent-backgrounding constructions (e.g. Siewierska 1984 for Slavic, and Dobrovie-Sorin 2005 for Romance). In what follows we show that the two agent-backgrounding constructions discussed here differ from reflexives in LSC. The nonagreeing central construction is clearly nonreflexive, as reflexives in LSC are marked by agreement with the body of the signer. The high-locus construction with animate patients, by contrast, does involve agreement with the signer's body and therefore shares a formal property with the reflexive. However, the high locus for the agent always corresponds to a reading with a nonspecific human agent in our LSC data, as in 50.

(50) JOANA, $\boldsymbol{3}_{\text {up }}$-SHOOT-1.

(high-locus construction)

'They shot Joana.'

To obtain a reflexive reading the verb has to be articulated in the lower referential plane. However, we found that in some contexts agreement with a low locus for the agent, as in example 51, allows both a reflexive reading (51a) and an impersonal reading (51b).

(51) JOANA, 3-SHOOT-1.

a. 'Joana shot herself.'

b. 'They shot Joana.'

(LSC)

The high-locus construction is therefore not the only means of marking agent reduction with an agreeing verb in LSC. Examples like 51 show that it is also possible to express a nonspecific human agent reading with an agreeing verb lacking a lexical agent, without assigning a high locus to the agent. But without a high locus for the agent, an example like 51, with articulation of the predicate toward the signer, is not limited to an impersonal reading.

Contexts that combine a reflexive and an impersonal construction in the same sentence show that the two readings differ with respect to other contrastive markings. While the first-person reflexive is articulated with eyegaze fixed on the addressee (52, Figure 16a), the nonspecific agent reading appears not only with a high locus but also with averted eyegaze (53). Example 53 further shows that eyegaze can reinforce the activation of a high locus that is already established by agreement (Figure 17).

(52) IX1 FINGER-CUT-1 FINGER-STRIP-1.

'I cut my finger and I put a bandage on my finger.' 


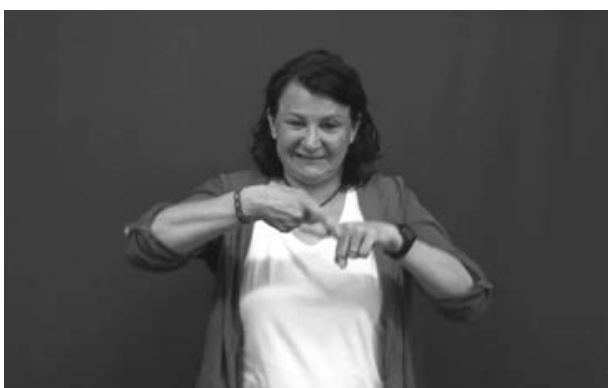

a. FINGER-CUT-1 with fixed eyegaze to addressee.

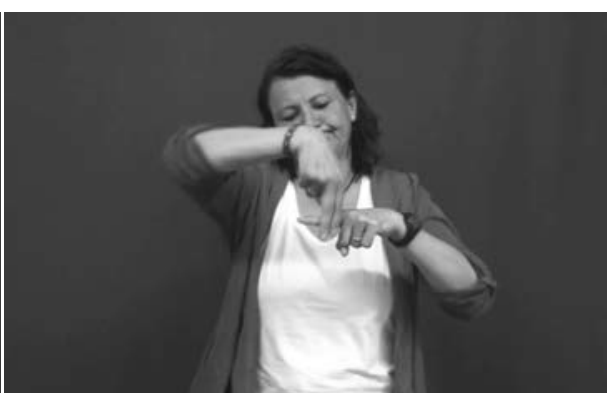

b. FINGER-STRIP-1.

FIGURE 16. Two reflexive predicates in one sentence.

(53) eg:up.cl

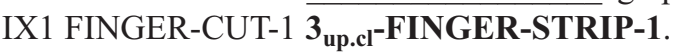

'I cut my finger and they put a bandage on my finger.'

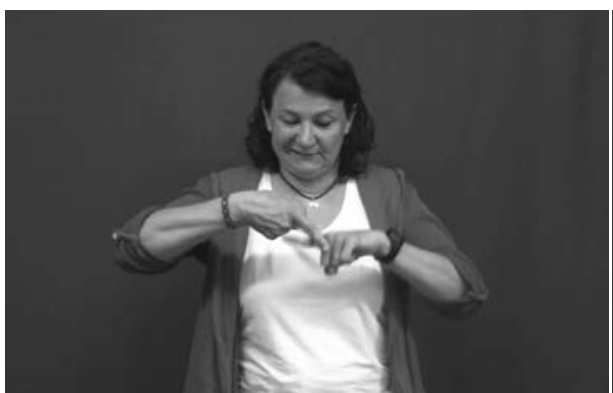

a. FINGER-CUT-1 with averted eyegaze.

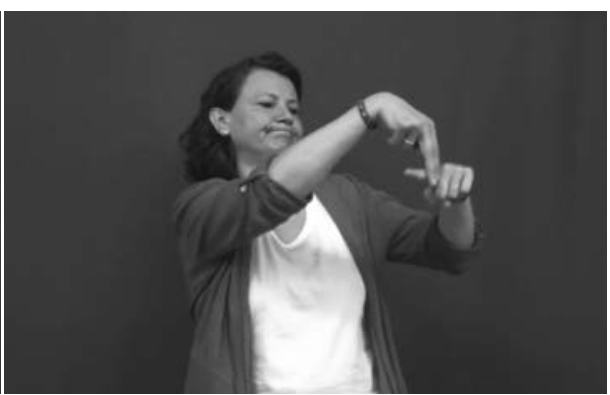

b. $3_{\text {up.cl }}$.FINGER-STRIP-1 at a high locus.

FIGURE 17. Combination of reflexive and impersonal construction in one sentence.

The pair of examples below illustrate a further marker that may contribute to disambiguation of examples like 51: the elicitation of the reflexive reading did not appear with body lean (54, Figure 18), while the patient DP in the high-locus construction was articulated with body lean to the contralateral side (marked by the subscript $\mathrm{cl}$ in 55, and see Figure 19).

br

(54) MARIA WASH-FACE-1.

'Maria washed her $_{i}$ face.'

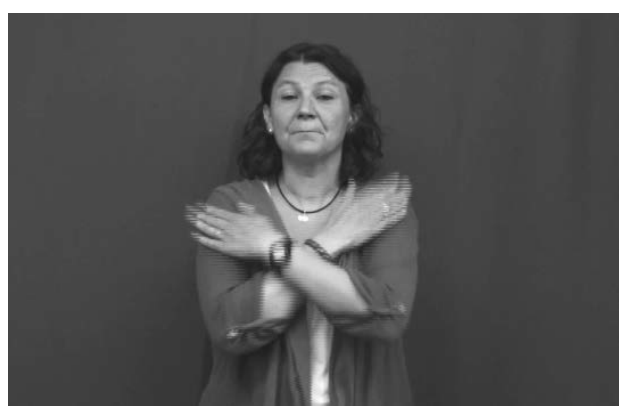

FIGURE 18. Sign for MARIA articulated without body lean. 
br

(55) $\overline{\text { MARIA }} 3_{\text {up }}$-WASH-FACE-1.

'They washed Maria's face.'

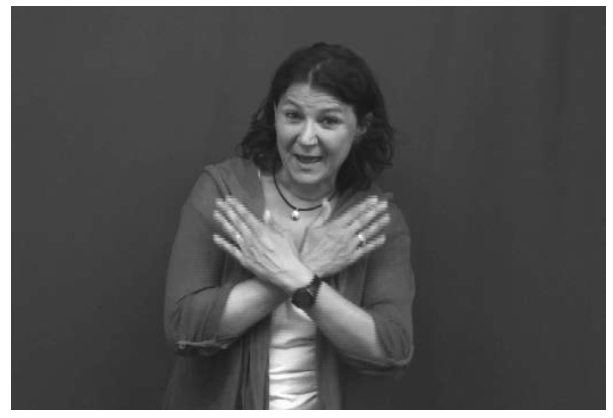

FIGURE 19. Sign for MARIA coarticulated with body lean.

Another minimal pair contrasting reflexive and nonspecific human agent interpretation differed in the distance of articulation from the body of the signer. The reflexive sentence is articulated without averted eyegaze or body lean, and with articulation of the verb close to the body of the signer (56, Figure 20), whereas the nonspecific agent interpretation is articulated with averted eyegaze and body lean, and the verb is articulated at a distance with respect to the body of the signer (57, Figure 21).

rs:joana

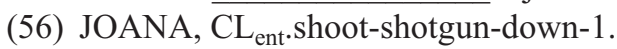

'Joana shot herself from below.'

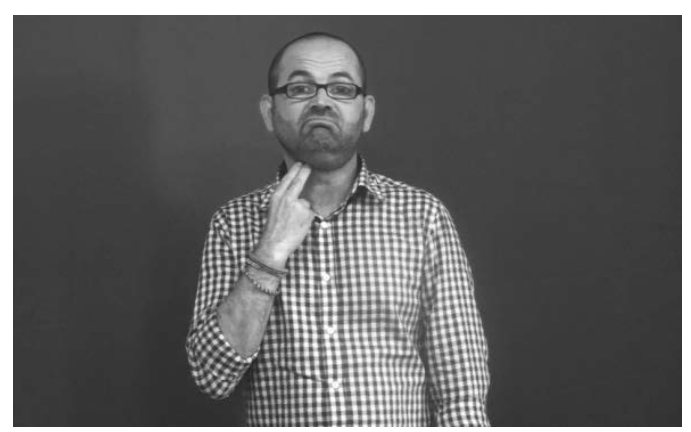

FIGURE 20. Close articulation to the body of the signer.

rs:joana

(57) JOANA $_{\text {ip }}, \overline{\text { 3-CL }} \mathbf{C L}_{\text {ent }}$ shot-gun-in-the-head-1.

'They aimed at Joana with a shotgun.'

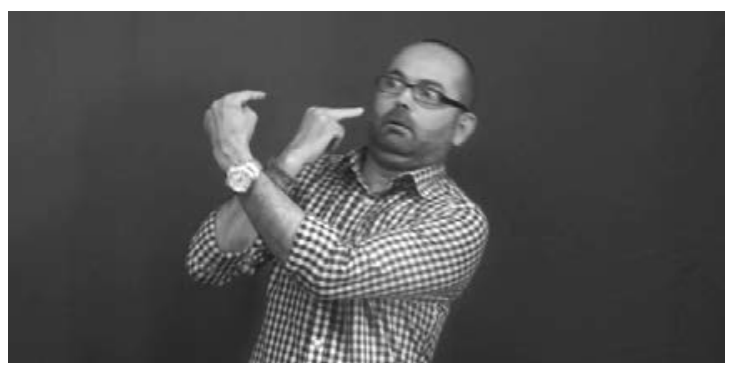

FIGURE 21. Distant articulation from the body of the signer. 
The minimal pairs differ in a number of features, summarized in Table $4 .{ }^{14}$ However, all of the elicited examples with nonspecific agents simultaneously combine more than one of these features. The only single factor disambiguating clearly in favor of an impersonal reading was the high locus for the agent. When we tested constructed minimal pairs that differed only on a single one of the features (averted eyegaze, body lean, or distance of articulation), the examples remained ambiguous. We leave the study of the exact role of these features in the disambiguation of agentless examples to further research.

$\begin{array}{lccc}\text { MORPHOSYNTAX } & \text { REFLEXIVE } & \text { IMPERSONAL } & \text { DISTINGUISHING } \\ \text { Averted eyegaze } & - & + & \checkmark \\ \text { Body lean } & - & + & \checkmark \\ \text { Distance from body } & - & + & \checkmark\end{array}$

TABLE 4. Distinguishing features between reflexive and impersonal structures.

To summarize, we have shown that the high-locus construction excludes a reflexive reading. But there is a third type of configuration that allows agent backgrounding in LSC, consisting of an agreeing verb without a lexical agent, articulated in the lower signing space. A first exploration of this configuration suggests that averted eyegaze, body lean, and distance of articulation from the body all play a role in the disambiguation between a reflexive and an impersonal interpretation. None of these factors, however, allows disambiguation by itself.

6. Discussion AND AnAlysis. The discussion above has shown that the high-locus construction preserves transitivity ( $\$ 5.3)$ and implies a human agent (\$5.1). Transitive predicates in this construction remain transitive, with a high empty locus corresponding to the implicit agent marked by agreement. The high-locus construction therefore clearly differs syntactically from a passive, since there is no reduction in transitivity for the underlying predicate. We propose to analyze this construction as involving a prosubject that is identified by agreement (as proposed for ASL in Lillo-Martin 1986, as well as Bahan et al. 2000) and interpreted as nonspecific due to the semantic specialization of the upper area in the frontal plane of the signing space for nonspecific nominal referents in LSC (Barberà 2012).

As we have shown above, the agreement need not be part of the lexical verb in LSC, as in $58 \mathrm{a}$, but can be provided by the auxiliary sign (58b) or identification of the high locus by the place of articulation of a nonagreeing verb (58c).

(58) a. pro $_{\text {up }}$ PATIENT_i up VERB

b. pro $_{\text {up }}$ PATIENT_i up VERB up AUX

(agreeing verb)

c. pro $_{\text {up }}$ PATIENT_i upVERB

(auxiliary agreement sign)

(high articulation of plain verb)

\footnotetext{
${ }^{14}$ We also tested compatibility with markers of intentionality or lack thereof. However, these markers do not discriminate between reflexive and R-impersonal interpretations. Under both interpretations, intentionality or lack thereof is attributed to the agent of the sentence.
}

br

(i) JOANA SHOOT-1 WANT.

a. 'Joana shot herself intentionally.'

b. 'They shot Joana intentionally.' br

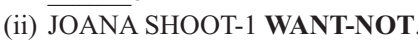

a. 'Joana shot herself unintentionally.'

b. 'They shot Joana unintentionally.' 
According to our proposal, the high-locus construction is parallel to R-impersonal subject constructions with a third plural subject like They stole my bike in English. This proposal is supported by the fact that (like third plural R-impersonal constructions crosslinguistically; see Siewierska 2011) the high-locus construction is limited to human agents (\$5.1).

As with a lexical subject, the patient DP in the high-locus construction can be in situ $(59 \mathrm{a}, \mathrm{c})$ or topicalized $(56 \mathrm{~b}, \mathrm{~d})$.

(59) a. JOHN $_{\mathrm{j}}$ MARY $_{\mathrm{i}} 3_{\mathrm{j}}-\mathrm{SEE}-3_{\mathrm{i}}$.

'John saw Mary.' br

b. $\overline{\text { MAR }} \mathbf{Y}_{\mathrm{i}} \mathrm{JOHN}_{\mathrm{j}} 3_{\mathrm{j}}$-SEE- $3_{\mathrm{i}}$. 'Mary, John saw her.'

(transitive + topicalized patient)

c. pro_up MARY ${ }_{\mathbf{i}} 3_{\text {up.j }}$-SEE- $3_{i}$.

'They saw Mary.' br

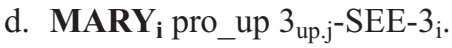
'Mary, they saw her.'

(transitive + patient in situ)

(R-impersonal + patient in situ)

(R-impersonal + topicalized patient)

As we have seen in $§ 3$, the analyses in Janzen et al. 2001, Kegl 1990, and Saeed \& Leeson 1999 consider the shift of perspective to the patient by means of role shift to be a central property of agent-demoting constructions. However, we do not consider role shift a defining property of the high-locus construction. Following Sze (2010), we propose that the use of role shift is an epiphenomenon triggered by animate patients. In general, sentences with inanimate themes/patients do not contribute to role-shift structures (with the exception of poetical and storytelling contexts, which are also known to license animate interpretation for inanimate objects in spoken languages).

The shift in perspective cannot be taken as an analogue of the syntactic promotion of the patient typical of promotional passives, since in LSC the center of perspective need not coincide with the agent. As example 60 shows, transitive structures can adopt the perspective of the patient.

(60) MARTÍ PAU SHOULDER GRAB-1.

'Martí grabbed Pau by the shoulder.'

Additionally, the center of perspective is not necessarily associated with the grammatical subject crosslinguistically. In the following examples the center of perspective is expressed as an object (61a) and as a prepositional phrase (61b). Shift of perspective to the patient therefore cannot be analyzed as an indicator of syntactic promotion of the object.

(61) a. Thunder frightens me.

b. For the child, the sweets in the jar were very tempting.

We have shown that the nonagreeing central construction does not pattern with passives since it allows anticausative interpretations, which present the event as agentless. At the same time, this construction also has interpretations with a semantically active implicit agent, since it allows agentive modification by purpose clauses and as complement to the predicate WANT ( 55.2$)$. Furthermore, in the nonagreeing central construction only the patient argument is associated with a locus in signing space. We propose to analyze this construction as an intransitivized middle verb that allows anticausative (62a), property middle (62b), and passive (62c) interpretations (i.e. interpretations with or without an implicit agent). 
(62) a. POT BREAK ALONE. $_{\mathbf{c}}$

(LSC; anticausative)

'The pot broke spontaneously.'

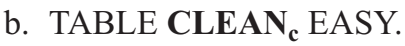

(LSC; property middle)

'(This) table cleans easily/is easy to clean.'

[for a table in a shop that was never cleaned]

(Passive is also possible: '(This) table was cleaned easily.')

c. TABLE CLEAN $\mathbf{N}_{\mathbf{c}}$ YESTERDAY.

'The table was cleaned yesterday.'

We propose that the nonagreeing central construction is an instance of argument reduction by projection of an intransitive structure for a transitive predicate. This kind of argument reduction is exemplified by the mediopassive found in Basque (Ortiz de Urbina 2003, Trask 1985, and references therein). Basque has two auxiliaries: edun 'AUX ${ }_{\text {TRANS }}$ '

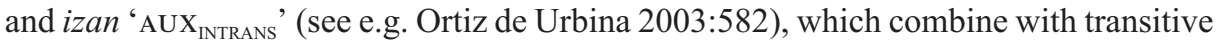
$(63 \mathrm{a}, \mathrm{b})$ and intransitive $(63 \mathrm{c})$ predicates, respectively. Combining a TRANSITIVE predicate with an INTRANSITIVE auxiliary gives rise to passive interpretations $(64 a, b)$ and anticausative interpretations (64b) if the predicate is compatible with this reading.

(63) a. Etxea bost hilabetetan eraiki zuten langileek.

house five months.LOC build $\mathrm{AUX}_{\text {TRANS }} 3 \mathrm{~A} / 3 \mathrm{E}$.PL workers.ERG

'The workers built the house in five months.'

(transitive verb and auxiliary; Ortiz de Urbina 2003, ex. 1275a)

b. Haurrak liburuak galdu ditu.

child.DET.ERG book.DET.PL lose.PRF AUX $\mathrm{TRANS}_{\text {. }}$ 3A.PL/3E

'The child lost the books.' (transitive verb and auxiliary; Trask 1985:987, ex. 8a)

c. Gizona etxera joan da.

man.DET house.to.go.PRF AUX $\mathrm{INTRANS}_{\text {. }} 3 \mathrm{~A}$

'The man went home.' (intransitive verb and auxiliary; Trask 1985:986, ex. 1)

(64) Transitive predicate with intransitive auxiliary

a. Etxea bost hilabetetan eraiki zen.

house five months.LOC build $\mathrm{AUX}_{\text {INTRANS }} 3 \mathrm{~A}$

'The house was built in five months.'

(passive interpretation; Ortiz de Urbina 2003, ex. 1275b)

b. Liburuak galdu dira.

book.DET.PL lose.PRF AUX INTRANS 3 A.PL

'The books got lost/were lost.'

(anticausative interpretation preferred; Trask 1985:987, ex. 8b)

In many languages (e.g. Slavic and Romance), the middle semantics found with the nonagreeing central construction is expressed by a weak reflexive clitic on the verb (reflexive middles). In LSC, however, this construction does not involve reflexive marking. As in 65a,b below, canonical reflexive sentences are expressed by agreement with the body of the signer and role shift (together with averted eyegaze) (see §5.4), both features that are clearly absent in the nonagreeing central construction.

(65) a. JOHN IX3 FINGER FINGER-STRIP-1. rs:john

'John put a bandage on his finger.' rs: 1 st

b. IX1 FINGER IX1 FINGER-STRIP-1. 'I put a bandage on my finger.' 
The properties of the nonagreeing construction resemble reflexive verbs in Romance semantically $(66 \mathrm{a}-\mathrm{c})$ but not syntactically, since there is no reflexive marking. ${ }^{15}$

(66) a. El jarro se rompió.

(Spanish; anticausative) the jar REFL broke

'The jar broke.'

b. Este jarro se limpia fácilmente. this jar REFL clean easily

'This jar cleans easily/is easy to clean.'

c. Ayer se repararon varias lámparas. (Spanish; passive) yesterday REFL repaired.3PL many lamps

'Yesterday many lamps were repaired.'

An alternative analysis would be to claim that the nonagreeing central construction is ambiguous between two underlying structures: a transitive structure with an empty third plural subject, comparable to $67 \mathrm{a}$, and an intransitive structure with an anticausative reading, comparable to $67 \mathrm{~b} .{ }^{16}$

(67) a. They broke the vase.

b. The vase broke.

This analysis would predict that the nonagreeing central construction allows a transitive and an intransitive structure. We do not adopt this alternative analysis since the transitive use of the predicate BREAK with two lexical arguments clearly differs from an intransitive use of BREAK with respect to the locus of the patient DP. While with a transitively used predicate (like BREAK) the DP for 'vase' is localized laterally on the referential plane in signing space (68a), the DP in the nonagreeing central construction is localized at a central locus (68b). When signing space is not used topographically or contrastively, the central locus is the unmarked localization for arguments of one-place predicates, in most contexts.

(68) a. $\mathrm{JOHN}_{\mathrm{ip}} \mathrm{VASE}_{\mathrm{cl}}$ BREAK.

'John broke the vase.'

b. VASE BREAK .

'The vase broke.'

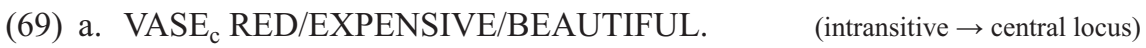

'The vase is red/expensive/beautiful.'

b. $\mathrm{VASE}_{\mathrm{c}}$ FELL.

(transitive $\rightarrow$ lateral locus)

(intransitive $\rightarrow$ central locus)

(intransitive $\rightarrow$ central locus)

'The vase fell.'

\footnotetext{
${ }^{15}$ For discussion of the different uses of the term middle see $\S 4$ above. The nonagreeing central construction in LSC is clearly not comparable to the construction that has been called middle in the literature on English. The English middle is limited to a stative property interpretation (Keyser \& Roeper 1984 and others), while the nonagreeing central construction has punctual eventive interpretations.

(i) a. This vase cleans easily.

(English middle)

b. He cleaned this vase.

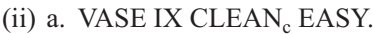

'This vase cleans easily.'

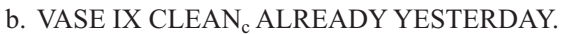

'This vase was cleaned yesterday.'

${ }^{16}$ A uniform transitive analysis of the nonagreeing central construction with a null third plural subject is not possible: the construction allows an anticausative, agentless interpretation and a passive interpretation with an inanimate cause, while crosslinguistically, impersonal third plural subjects impose an interpretation with a human implicit agent (Siewierska 2011).
} 
In the minimal pair in 68a,b, the patient DP VASE is not placed in the same locus: while with a transitive predicate BREAK the patient is localized laterally, with intransitive BREAK the theme is in a central location. The central localization of the theme VASE in $69 \mathrm{~b}$ suggests that VASE is the only DP on the central plane, as is generally the case with one-place predicates, such as FALL, RED, EXPENSIVE in 69a. Furthermore, there is no agreement that could identify the empty locus, and therefore the subject cannot be a subject of type pro $_{\text {up }}$.

We also discard an analysis of the nonagreeing construction as an adjectival passive since the construction allows eventive readings (62c) and modification of the implicit agent by 'on purpose' (39), while adjectival passives have a stative interpretation and are not generally compatible with modification by 'on purpose' (70a), in contrast with the copula passive in $70 \mathrm{~b}$.

(70) a. *El jarro está roto a propósito. (Spanish; adjectival passive) DET jar is.LOC broken on purpose

'The jar is broken on purpose.'

b. El jarro fue roto a propósito. (Spanish; auxiliary passive) DET jar is.COP broken on purpose

'The jar was broken on purpose.'

In LSC the nonagreeing construction is furthermore compatible with aspectual inflection on the verb conveying the meaning 'gradually'. In 71 the sign HUMID is modified with the bound inflectional morpheme 'gradual', further supporting the conclusion that it allows an eventive interpretation.

(71) CLOTHES WATER HUMID c.grad.

'The clothes are getting wet.'

The nonagreeing central construction therefore patterns with a verbal middle voice, as found in Basque, obtained by projection of an intransitive syntactic structure, and not with the reflexive middles found in Germanic, Romance, and Slavic (Dobrovie-Sorin 2005, Siewierska 1984, Steinbach 2002).

7. Conclusions. We have examined two agent-backgrounding constructions in LSC: the high-locus construction and the nonagreeing central construction. Semantically, the two constructions do not have the profile of a passive, since the high-locus construction is limited to human implicit agents and the nonagreeing central construction does not necessarily imply an agent, allowing anticausative as well as passive interpretations with human agents and inanimate causes.

In the high-locus construction an agreeing verb or a plain verb establishes an empty but syntactically active locus by the agreement path, and the backgrounded agent is obligatorily interpreted as human. With an animate patient the agreement in this construction is with the body of the signer, which expresses the patient through role shift, while for inanimate patients agreement is with the locus established for the inanimate patient DP. As there are no known markers of grammatical role in LSC, it is not possible to use syntactic promotion of the patient to syntactic subject as a test for intransitivity. The role shift observed with animate patients in the high-locus construction adds discursive prominence by taking the perspective of one of the participants. Role shift to the patient is not, however, a plausible marker of syntactic promotion of the patient, since in transitive sentences with fully referential animate arguments, role shift can target agents as well as patients, and furthermore role shift is observed only with animate patients. The high nonspecific location is established as an independent locus in LSC, as evidenced by the fact that it forces dissimilation with the preceding sign (see $§ 5.3$ 
above). Furthermore, the auxiliary agreement sign in LSC agrees with a high agent locus, further confirming a transitive analysis of the high-locus construction. Finally, it is worth mentioning that single-argument agreement also takes place even when the argument has not been previously activated, as shown by the high-locus construction with plain verbs.

The nonagreeing central construction, in contrast, is limited to plain verbs and allows a range of interpretations, including anticausative, stative-middle, and passive. We have argued that this construction corresponds to an argument-reducing construction by projecting an intransitive structure with a transitive predicate, as found for example in the mediopassive in Basque. This form is a nonactive verb (middle) that optionally, but not necessarily, includes an implicit agent, while the high-locus construction corresponds to a transitive construction with an R-impersonal subject.

The present exploration of agent-backgrounding operations in LSC has shown that there are various such structures, where different morphosyntactic features interact in order to express agentless structures. Recently, this domain has become the focus of attention of a number of other research projects (see Herrmann \& Steinbach 2015 for German Sign Language (DGS), Kimmelman 2015 for Sign Language of The Netherlands (NGT), Koulidobrova 2015 for ASL, and Özkul \& Kelepir 2015 for Turkish Sign Language (TID)). In preliminary research on agent-backgrounding structures and Rimpersonal constructions, it has been shown that in some contexts Spanish Sign Language (LSE) and French Sign Language (LSF) also display the use of high loci for R-impersonal subjects (Costello 2015 for LSE, and L'Huillier et al. 2015 for LSF). It is as yet not clear, however, whether this high location has a clear grammatical function in the grammar of these languages: for example, marking nonspecificity as in LSC. In the agent-backgrounding constructions in other sign languages, the empty agent need not be localized in a marked location in the upper plane, making these examples plausibly more similar to the low agentless construction in LSC, which has not so far been analyzed. The grammaticalization of the high nonspecific loci in LSC helps to make the transitive construction more visible in the case of high empty loci. If the other sign languages have agreement from a neutral lower locus, our argument about assimilation to a previous low locus does not necessarily go through, since the empty locus could stay at the same height in the signing space as the previous sign (contrary to what we see in LSC). The results reported here suggest that agent backgrounding in LSC shows language-specific properties related to the expression of nonspecificity, rather than modality-specific properties. Comparative studies on other sign languages are clearly needed for a better understanding of omitted agents in sign languages.

\section{REFERENCES}

Ackema, Peter, and Maaike Schoorlemmer. 2005. Middles. The Blackwell companion to syntax, vol. 3, ed. by Martin Everaert and Henk van Riemsdijk, 131-203. Oxford: Blackwell.

Bahan, Benjamin; Judy Kegl; Robert G. Lee; Dawn Maclaughlin; and Carol NeiDLE. 2000. The licensing of null arguments in American Sign Language. Linguistic Inquiry 31.1-27. DOI: 10.1162/002438900554271.

Baker, Mark; Kyle Johnson; and IAn Roberts. 1989. Passive arguments raised. Linguistic Inquiry 20.219-51. Online: http://www.jstor.org/stable/4178625.

Baker-Shenk, Charlotte Lee, and Dennis Cokely. 1980. American Sign Language: A teacher's resource text on grammar and culture. Silver Spring, MD: T. J. Publishers.

Barberà, Gemma. 2012. The meaning of space in Catalan Sign Language (LSC): Reference, specificity and structure in signed discourse. Barcelona: Universitat Pompeu Fabra dissertation. [Published, Berlin: De Gruyter Mouton and Ishara Press, 2015.] 
BarberÀ, Gemma, and Patricia Cabredo HofHerr. 2016. Une structure de mise en arrièreplan de l'agent en langue des signes catalane (LSC): Passif ou impersonnel? L'information grammaticale $149.55-60$.

Barberà, Gemma, and Patricia Cabredo Hofherr. 2017. Two indefinite pronouns in Catalan Sign Language (LSC). Proceedings of Sinn und Bedeutung 21, to appear.

BARBERÀ, Gemma, and JoseP QUer. 2013. Impersonal reference in Catalan Sign Language (LSC). Sign language research uses and practices: Crossing views on theoretical and applied sign language linguistics, ed. by Laurence Meurant, Aurélie Sinte, Mieke van Herreweghe, and Myriam Vermeerbergen, 237-58. Berlin: De Gruyter Mouton and Ishara Press.

Benedicto, Elena, and Diane Brentari. 2004. Where did all the arguments go? Argument-changing properties of classifiers in ASL. Natural Language and Linguistic Theory 22.743-810. DOI: 10.1007/s11049-003-4698-2.

Benedicto, Elena; Sandra Cvejanov; and Josep Quer. 2007. Valency in classifier predicates: A syntactic analysis. Lingua 117.1202-15. DOI: 10.1016/j.lingua.2005.06.012.

Blevins, James P. 2003. Passives and impersonals. Journal of Linguistics 39.473-520. DOI: $10.1017 /$ S0022226703002081.

Bolinger, Dwight. 1979. To catch a metaphor: You as norm. American Speech 54.194209. DOI: $10.2307 / 454949$.

Cabredo Hofherr, Patricia. 2006. 'Arbitrary' pro and the theory of pro-drop. Arguments and agreement, ed. by Peter Ackema, Patrick Brandt, Maaike Schoorlemmer, and Fred Weermann, 230-58. Oxford: Oxford University Press.

Cabredo HofHerr, Patricia. 2017. Impersonal passives. The Blackwell companion to syntax, 2nd edn., ed. by Martin Everaert and Henk Van Riemsdijk. Oxford: Blackwell, to appear.

Сномsкy, Noam. 1981. Lectures on government and binding. Dordrecht: Foris.

Costello, Brendan. 2015. How do you/we/they get impersonal in Spanish Sign Language (LSE)? A first look. Paper presented at the workshop Langues des Signes et R-Impersonnels, Université Paris 8, February 6.

COSTELLO, BRENDAN. 2016. Language and modality: Effects of the use of space in the agreement system of lengua de signos española (Spanish Sign Language). Utrecht: LOT.

Cuxac, Christian. 2000. La langue des signes française: Les voies de l'iconicité. Faits de langue, vols. 15-16. Paris: Ophrys.

Dobrovie-Sorin, Carmen. 1998. Impersonal se constructions in Romance and the passivization of unergatives. Linguistic Inquiry 29.399-437. DOI: 10.1162/002438998553 806.

Dobrovie-Sorin, CARmen. 2005. The se anaphor and its role in argument realization. The Blackwell companion to syntax, vol. 4, ed. by Martin Everaert and Henk van Riemsdijk, 118-79. Oxford: Blackwell.

Engberg-Pedersen, Elisabeth. 1993. Space in Danish Sign Language: The semantics and morphosyntax of the use of space in a visual language. Hamburg: Signum.

GAST, VOLKER, and Johan VAN DER AUwERA. 2013. Towards a typology of human impersonal pronouns, based on data from European languages. Languages across boundaries: Studies in memory of Anna Siewierska, ed. by Dik Bakker and Martin Haspelmath, 11958. Berlin: De Gruyter Mouton.

Geraci, Carlo. 2014. Spatial syntax in your hands. North East Linguistic Society (NELS) 44(1).123-34.

Geraci, Carlo, and Josep Quer. 2014. Determining argument structure in sign languages. Structuring the argument: Multidisciplinary research on verb argument structure, ed. by Asaf Bachrach, Isabelle Roy, and Linnaea Stockall, 45-60. Amsterdam: John Benjamins.

Guitteny, Pierre. 2006. Le passif en langue des signes. Bordeaux: Université Bordeaux III dissertation.

Hansen, Martje. 2007. Warum braucht die Deutsche Gebärdensprache kein Passiv? Verfahren der Markierung semantischer Rollen in der DGS [Why can German Sign Language (DGS) do without a passive construction? Ways of marking semantic roles in DGS] (Dissertation abstract). Sign Language \& Linguistics 10(2).213-22. DOI: 10 $.1075 /$ sll.10.2.09han. 
Herrmann, AnNika, and Markus Steinbach. 2015. Impersonal reference in German Sign Language. Paper presented at the workshop Langues des Signes et R-Impersonnels, Université Paris 8, February 6.

HolmberG, ANDERs. 2005. Is there a little pro? Evidence from Finnish. Linguistic Inquiry 36.533-64. DOI: 10.1162/002438905774464322.

JAEGGli, Osvaldo A. 1986. Passive. Linguistic Inquiry 17.587-622. Online: http://www .jstor.org/stable/4178510.

Janzen, Terry; Barbara O'Dea; and Barbara Shaffer. 2001. The construal of events: Passives in American Sign Language. Sign Language Studies 1.281-310. DOI: 10.1353 /sls.2001.0009.

Keenan, Ed, and Matthew Dryer. 2007. Passive in the world's languages. Language typology and syntactic description, vol. 1: Clause structure, ed. by Timothy Shopen, 32561. Cambridge: Cambridge University Press.

KegL, Judy. 1990. Predicate argument structure and verb-class organization in the ASL lexicon. Sign language research: Theoretical issues, ed. by Ceil Lucas, 149-75. Washington, DC: Gallaudet University Press.

Kemmer, Suzanne. 1993. The middle voice. Amsterdam: John Benjamins.

Keyser, Samuel Jay, and Tom Roeper. 1984. On the middle and ergative constructions in English. Linguistic Inquiry 15.381-416. Online: http://www.jstor.org/stable/4178392.

Kimmelman, VAdim. 2015. R-impersonals in Sign Language of the Netherlands. Paper presented at the workshop Langues des Signes et R-Impersonnels, Université Paris 8, February 6 .

Kitagawa, Chisato, and Adrienne Lehrer. 1990. Impersonal uses of personal pronouns. Journal of Pragmatics 14.739-59. DOI: 10.1016/0378-2166(90)90004-W.

Klima, Edward, and Ursula Bellugi. 1979. The signs of language. Cambridge, MA: Harvard University Press.

KoEnig, JeAn-Pierre. 1999. On a tué le président! Ultra-indefinites and the nature of passives. Cognition and function in language, ed. by Barbara Fox, Dan Jurafsky, and Laura A. Michaelis, 235-51. Stanford, CA: CSLI publications.

Koulidobrova, Helen. 2015. Searching for the person in ASL impersonals. Paper presented at the workshop Langues des Signes et R-Impersonnels, Université Paris 8, February 6 .

Kulikov, LEONID. 2013. Middles and reflexives. The Bloomsbury companion to syntax, ed. by Silvia Luraghi and Claudia Parodi, 261-80. London: Continuum.

L'Huillier, Marie-Thérèse; Marie-Anne Sallandre; and Brigitte Garcia. 2015. Impersonal reference to humans in LSF: A first glance. Paper presented at the workshop Langues des Signes et R-Impersonnels, Université Paris 8, February 6.

Lillo-Martin, Diane. 1986. Two kinds of null arguments in American Sign Language. Natural Language and Linguistic Theory 4.415-44. DOI: 10.1007/BF00134469.

Lillo-Martin, Diane. 2012. Utterance reports and constructed action. In Pfau et al., 36586.

Malamud, Sophia A. 2012. Impersonal indexicals: one, you, man, and du. Journal of Comparative Germanic Linguistics 15.1-48. DOI: 10.1007/s10828-012-9047-6.

Mathur, Gaurav, and Christian Rathmann. 2012. Verb agreement. In Pfau et al., 13657.

Ortiz DE Urbina, Jon. 2003. Impersonal clauses. A grammar of Basque, ed. by José Ignacio Hualde and Jon Ortiz de Urbina, 572-91. Berlin: De Gruyter Mouton.

Özkul, Asli, and Meltem Kelepir. 2015. Passive-like constructions with inanimate themes in Turkish Sign Language (TID). Poster presented at Formal and Experimental Approaches to Sign Language Theory, Universitat Pompeu Fabra, Barcelona, May 4.

PAdDEN, CAROL. 1990. The relation between space and grammar in ASL morphology. Proceedings of the Second International Conference on Theoretical Issues in Sign Language Research, ed. by Ceil Lucas, 118-32. Washington, DC: Gallaudet University Press.

Perlmutter, David M., and Paul M. Postal. 1984. Impersonal passives and some relational laws. Studies in relational grammar 2, ed. by David M. Perlmutter and Carol G. Rosen, 126-70. Chicago: Chicago University Press.

Pfau, Roland; Markus Steinbach; and Bencie Woll (eds.) 2012. Sign language: An international handbook. Berlin: De Gruyter. 
QuAdros, Ronice Müller De, and Josep Quer. 2008. Back to back(wards) and moving on: On agreement, auxiliaries and verb classes in sign languages. Sign languages: Spinning and unraveling the past, present and future (TISLR 9), ed. by Ronice Müller de Quadros, 530-51. Petrópolis: Editora Arara Azul. Online: http://www.editora-arara-azul.com.br /ebooks/catalogo/complete.pdf.

QUER, JosEP. 2011. Reporting and quoting in signed discourse. Understanding quotation (Mouton series in pragmatics), ed. by Elke Brendel, Jörg Meibauer, and Markus Steinbach, 277-302. Berlin: Mouton de Gruyter.

Saeed, John I., and LorRaine LeEson. 1999. Detransitivisation in Irish Sign Language. Paper presented at the European Science Foundation Intersign Meeting on Morphosyntax, Siena, March 1999.

Siewierska, AnNa. 1984. The passive: A comparative linguistic analysis. London: Routledge.

SIEWIERSKA, ANNA. 2008. Introduction: Impersonalization from a subject-centred vs. agentcentred perspective. Transactions of the Philological Society 106.115-37. DOI: 10.1111 /j.1467-968X.2008.00211.x.

SiEWIERSKa, ANNA. 2011. Overlap and complementarity in reference impersonals: 'Man'constructions vs. third person plural-impersonals in the languages of Europe. Impersonal constructions: A cross-linguistic perspective, ed. by Anna Siewierska and Andrej Malchukov, 57-89. Amsterdam: John Benjamins.

Steinbach, Markus. 2002. Middle voice: A comparative study in the syntax-semantics interface in German. Amsterdam: John Benjamins.

Steinbach, Markus, and Roland Pfau. 2007. Grammaticalization of auxiliaries in sign languages. Visible variation: Comparative studies on sign language structure, ed. by Pamela Perniss, Roland Pfau, and Markus Steinbach, 303-39. Berlin: De Gruyter Mouton.

Sze, Felix. 2010. Is there passive in Hong Kong Sign Language? Poster presented at TISLR 10, Purdue University, 30 September-2 October 2010.

Trask, LARRY. 1985. The Basque passive: A correct description. Linguistics 2.985-91. DOI: 10.1515/ling.1985.23.6.985.

Yule, George. 1982. Interpreting anaphora without identifying reference. Journal of Semantics 1.315-22. DOI: 10.1093/jos/1.3-4.315.

Zifonun, Gisela. 2000. ,Man lebt nur einmal': Morphosyntax und Semantik des Pronomens man. Deutsche Sprache 28.232-53. Online: http://nbn-resolving.de/urn:nbn:de :bsz:mh39-48435.

Zwitserlood, Inge. 2012. Classifiers. In Pfau et al., 158-85.

Zwitserlood, Inge, and Ingeborg Van GiJn. 2006. Agreement phenomena in Sign Language of the Netherlands. Arguments and agreement, ed. by Peter Ackema, Patrick Brandt, Maaike Schoorlemmer, and Fred Weermann, 195-229. Oxford: Oxford University Press.

UMR 7023 Structures Formelles du Langage

CNRS UPS-Pouchet

59/61, rue Pouchet

75017 Paris, France

[gemma.barbera@upf.edu]

[patricia.cabredo-hofherr@enrs.fr]
[Received 23 September 2015; revision invited 16 March 2016; revision received 12 July 2016 ; accepted 23 November 2016] 